\title{
Desinformación y derechos de autor: una coexistencia difícil
}

\author{
$* * * *$ \\ Nicola Lucchi \\ Universidad Pompeu Fabra \\ nicola.lucchi@upf.edu \\ Enrico Bonadio \\ City University of London \\ Enrico.Bonadio.1@city.ac.uk \\ Oreste Pollicino \\ Università Bocconi \\ oreste.pollicino@unibocconi.it
}

Recibido: 28 de octubre de 2021

Aceptado: 30 de noviembre de 2021

\section{Resumen}

Como es bien sabido, las nuevas tecnologías han cambiado profundamente la forma en que se elabora, comparte y difunden contenidos. Uno de los cambios más recientes (y preocupantes) es el fenómeno de las "noticias falsas", especialmente desde que la desinformación y la tergiversación intencional de información real han comenzado a afectar la toma de decisiones individuales en la esfera política. Es un fenómeno preocupante debido a que la difusión de noticias falsas puede poner en riesgo los valores democráticos y socavar la seguridad nacional.

En este contexto cabe preguntarse: ¿pueden los derechos de autor desempeñar un rol en la lucha contra las noticias falsas? Y, preliminarmente, ¿cuál es la relación entre esas noticias y los derechos de autor?

En teoría, las noticias falsas caen dentro del objeto de protección de los derechos de autor y, a menudo, pueden cumplir con sus requisitos de protección. El presente artículo analiza tres noticias falsas recientes que se han difundido ampliamente en línea, poniendo de relieve que los derechos de autor pueden subsistir en tales 
noticias. El primer ejemplo es un breve artículo, mientras que los otros dos ejemplos se refieren a una fotografía modificada digitalmente y un video. No obstante que estas noticias sean potencialmente susceptibles de protección por derechos autorales, proponemos eliminar cualquier derecho de este tipo que pueda surgir, y ello por motivos de interés público. De hecho, cuando una obra goza de protección de derechos de autor, sus titulares tienen un incentivo para explotarla, ya que el monopolio que se les otorga les permite obtener beneficios de la obra, por ejemplo, mediante licencias. Esto puede contribuir a alentar a los creadores de noticias falsas a difundirlas de manera exponencial a través de múltiples canales para llegar a un público amplio. Por lo tanto, excluir los derechos de autor podría contribuir a que las noticias falsas sean menos atractivas. En este artículo también se hará una breve referencia a las defensas de los derechos de autor que las entidades e individuos que verifican la veracidad de las noticias (verificadores de hechos) pueden hacer valer, es decir, la doctrina del uso justo según la ley de los Estados Unidos y varias excepciones disponibles en la legislación de la Unión Europea (y el Reino Unido), a saber, el uso transitorio, la extracción de textos y datos, la excepción de crítica y revisión y de seguridad pública.

Palabras clave: derecho de autor, propiedad intelectual, fake news, desinformación, libertad de expresión.

\title{
Disinformation and Copyright: A Difficult Coexistence
}

\begin{abstract}
As is well known, new technologies have fundamentally changed the way content is produced, shared and distributed. One of the most recent (and worrying) changes is the phenomenon of "fake news", especially since misinformation and the deliberate misrepresentation of genuine information have begun to influence individual decision-making in the political sphere. It is a worrying phenomenon because the spread of fake news can endanger democratic values and undermine national security.

In this context, it is worth asking whether copyright law can play a role in the fight against fake news? And most importantly, what is the relationship between such news and copyright law?

In theory, fake news falls within the scope of copyright protection and can often meet your protection requirements. This article looks at three recent fake news stories that have become widespread on the internet and demonstrates that such news can be protected by copyright. The first example is a short article, while the other two examples relate to a digitally altered photograph and a video. Although [these messages] are potentially copyrightable, we suggest that any rights of this nature that might arise should be removed, on public interest grounds. This is because when a work enjoys copyright protection, its owners have an incentive
\end{abstract}


to exploit it, as the monopoly granted to them allows them to take advantage of the work, for example through licensing. This may encourage the creators of fake news to disseminate it exponentially through multiple channels in order to reach a large audience. Copyright exclusion could therefore make fake news less attractive. The article also briefly discusses the copyright defenses that entities and individuals who check the truth of news (fact-checkers) can assert, namely the doctrine of fair use under US law and various exceptions available under EU (and UK) law, namely transient use, data and text extraction, the criticism and review exception and public safety.

Key words: copyright, intellectual property, fake news, disinformation, free speech.

\section{Desinformação e direitos autorais: uma difícil convivencia}

\section{Resumo}

Como é sabido, as novas tecnologias mudaram fundamentalmente a forma como o conteúdo é produzido, compartilhado e distribuído. Uma das mudanças mais recentes (e preocupantes) é o fenômeno das "notícias falsas", especialmente porque a desinformação e a deturpação deliberada de informações genuínas começaram a influenciar a tomada de decisão individual na esfera política. É um fenômeno preocupante porque a disseminação de notícias falsas pode colocar em risco os valores democráticos e minar a segurança nacional.

Nesse contexto, vale a pena perguntar se a lei de direitos autorais pode desempenhar um papel na luta contra as notícias falsas. E o mais importante, qual é a relação entre essas notícias e a lei de direitos autorais?

Em teoria, o fake news se enquadra no escopo da proteção de direitos autorais e muitas vezes pode atender aos seus requisitos de proteção. Este artigo analisa três histórias recentes do fake news que se espalharam pela internet e demonstra que tais notícias podem ser protegidas por direitos autorais. $\mathrm{O}$ primeiro exemplo é um pequeno artigo, enquanto os outros dois exemplos se referem a uma fotografia alterada digitalmente e a um vídeo. Embora [essas mensagens] sejam potencialmente protegidas por direitos autorais, sugerimos que quaisquer direitos dessa natureza que possam surgir sejam removidos, por motivos de interesse público. Isso porque, quando uma obra goza de proteção de direitos autorais, seus proprietários têm um incentivo para explorá-la, pois o monopólio que lhes é concedido permite o aproveitamento da obra, por exemplo, por meio de licenciamento. Isso pode encorajar os criadores do fake news a divulgá-lo exponencialmente por meio de vários canais para atingir um grande público. A exclusão de direitos autorais pode, portanto, tornar as Notícias Falsas menos atraentes. O artigo também discute resumidamente as defesas de direitos autorais que entidades e indivíduos que verificam a verdade das notícias (verificadores de fatos) podem afirmar, nomeadamente a doutrina do uso justo ao abrigo da lei dos EUA e várias exceçóes disponíveis ao abrigo da lei 
da UE (e do Reino Unido), nomeadamente o uso transitório , extração de dados e texto, exceção de crítica e revisão e segurança pública.

Palavras-chave: direitos autorais, propriedade intelectual, notícias falsas, desinformação, liberdade de expressão.

\section{Introducción}

Como es bien sabido, las nuevas tecnologías han cambiado profundamente la forma en que se produce, comparte y difunde el contenido. Uno de los cambios más recientes (y preocupantes) es el fenómeno de las "noticias falsas". El argumento ha atraído una gran atención, especialmente desde que la desinformación y la tergiversación intencional de información real han comenzado a afectar la toma de decisiones individuales en la esfera política (Timmer, 2017, p. 670). De hecho, la desinformación puede explotarse como un poderoso instrumento para manipular la opinión pública y socavar el proceso democrático, ya que puede utilizarse incluso para influir en el resultado de las elecciones. Existe la creencia generalizada de que las noticias falsas podrían haber alterado el resultado de importantes eventos democráticos, como el referéndum del Brexit en el Reino Unido y las elecciones presidenciales de Estados Unidos (EE. UU.) de 2016 (Allcott y Gentzkow, 2017, p. 211). Además, la reciente pandemia de COVID-19 ha provocado desinformación sobre su origen, propagación y prevención: en tal sentido, la "infodemia" y la desinformación en la lucha contra la COVID-19 pueden ser tan perjudiciales para la salud humana y la seguridad pública como la misma pandemia (Lewis, 2020).

La motivación para la elaboración de noticias falsas no es solo sociopolítica o ideológica (Gu et al., 2017). La realización de este tipo de contenido se ha industrializado, mecanizado e incluso orientado de alguna manera por empresarios que "engañan a los usuarios de internet con información falsa mientras ganan importantes sumas de dinero" (Sanders y Jones, 2018). Existe una creciente evidencia que señala el surgimiento de ecosistemas de publicidad digital que facilitan e incentivan la creación de noticias falsas, especialmente dentro de las redes sociales (Braun y Ecklund, 2019; Chiou y Tucker, 2018; Haenschen y Ellenbogen, 2016; Ohlheiser, 2016; Pickard, 2020, p. 
123; Schulte, 2020, p. 133; Size, 2020, p. 40; Tynan 2016). Por lo tanto, los usuarios de la información pueden quedar sujetos al impacto negativo del (creciente) poder que "las empresas de redes sociales, como Google, Apple, Facebook y Amazon han ganado para controlar quién publica, qué, a quién y cómo se monetizan las publicaciones" (Figueira y Oliveira, 2017, p. 818). Del mismo modo, se ha permitido que una industria realmente disruptiva de noticias falsas florezca como una criatura comercial independiente en el mercado de las noticias (Figueira y Oliveira, 2017, p. 819).

El debate sobre cómo deberían responder los reguladores a este fenómeno es candente. Existe una larga historia de intervenciones gubernamentales en los mercados de noticias a través de herramientas de política de competencia, ayudas estatales y regulación. Los Gobiernos han intentado recientemente responsabilizar a las plataformas en línea de mantener y/o difundir contenido intencionalmente engañoso, promulgando leyes contra las noticias falsas (Pitruzzella y Pollicino, 2020); ${ }^{1}$ sin embargo, queda por ver si estos métodos son realmente efectivos para reducir la desinformación en línea (Alemanno, 2018). Parece necesario diseñar e implementar medidas dirigidas a los modelos de negocio de las fake news para oponerse al círculo vicioso que lleva a su creación y evitar que dichas noticias se conviertan en "una opción económica atractiva" (Kshetri y Voas, 2017, p. 10). Sin embargo, estas medidas pueden ser difíciles de introducir en jurisdicciones como Estados Unidos, que protegen fuertemente la libertad de expresión.

1 Ver e.g. las leyes contra las noticias falsas recientemente adoptadas o discutidas en diferentes países, incluida la Ley de Aplicación de la Red alemana "NetzDG"; la Ley Orgánica francesa núm. 2018-1201, de 22 de diciembre de 2018, relativa a la lucha contra la manipulación de la información (Loi organique $\mathrm{n}^{\circ} 2018$-1201 del 22 de diciembre de 2018 relativa a la lutte contre la manipulation de l'information); la Ley Federal de Rusia sobre Enmiendas al Artículo 153 de la Ley Federal de Información, Tecnología de la Información y Protección de la Información, de 18 de marzo de 2019; el proyecto de ley de Singapur No. 10/2019 (Deliberate Online Falsehoods Bill); the Malaysia's Anti-Fake News Act of 2018. Ver también: Austria-based International Press Institute, que ha publicado una lista de países que han aprobado regulaciones de "noticias falsas" durante la pandemia de COVID-19. Ver la tabla en: https://ipi.media/covid19-media-freedom-monitoring/. 
Dicho esto, ¿pueden los derechos de autor jugar un rol en la lucha contra las noticias falsas? y ¿cuál es la relación entre esas noticias y los derechos de autor? Algunas de estas noticias, en teoría, quedan comprendidas en el objeto del derecho de autor y podrían satisfacer con los requisitos de protección. No obstante ello, proponemos eliminar cualquier protección por derecho de autor que pueda surgir por motivos de interés público. Como es sabido, cuando una obra está protegida por derechos de autor, los titulares de dichos derechos tienen un incentivo para explotarla, ya que el monopolio que se les otorga a menudo permite maximizar los beneficios de la obra, por ejemplo, mediante la concesión de licencias.

Esto podría alentar a los creadores de noticias falsas a difundirlas de manera exponencial a través de múltiples canales para llegar a un público amplio, especialmente a través de internet y/o redes sociales. Por lo tanto, excluir los derechos de autor podría contribuir a que las noticias falsas sean menos atractivas. La razón de peso para negar la tutela autoral es que las noticias falsas no contribuyen al bienestar de la sociedad y, por lo tanto, no deben incentivarse ofreciendo un monopolio que ayude a los creadores a aumentar las ganancias. De hecho, las noticias falsas pueden poner seriamente en riesgo los valores democráticos y socavar la seguridad nacional, lo que también genera temores por el derecho a la privacidad y a la autonomía de los usuarios, que están a la base del derecho a la dignidad de las personas. Si, en cambio, asumimos que los derechos de autor subsisten en este tipo de contenido y su titular optara por ejercerlos, también es importante aclarar qué defensas pueden oponer los verificadores de hechos, es decir, las organizaciones y las personas que verifican la veracidad de las noticias falsas, es decir, quiénes podrían verse implicados en litigios iniciados por los creadores de tales noticias.

El artículo está estructurado de la siguiente manera. El apartado 2 proporciona una definición y taxonomía de las noticias falsas y destaca el modelo de negocio rentable en el que se basa. El apartado 3 se centra en los diferentes enfoques seguidos en los EE. UU. y en Europa cuando se trata de regular la libertad de expresión y/o de abordar la desinformación. Luego, el análisis pasa a las cuestiones que emergen en relación con los derechos de autor. El apartado 4 señala que varias formas de noticias falsas, a saber, un artículo corto, 
una fotografía o un video modificado digitalmente pueden considerarse una obra protegida por derechos de autor y que pueden satisfacer los requisitos de protección. El apartado 5 se centra en algunas excepciones que podrían ser invocadas por los verificadores de hechos para eludir la responsabilidad por infracción de los derechos de autor, es decir, la doctrina del uso justo según la ley de los EE. UU. y varias excepciones disponibles en la legislación de la UE (y el Reino Unido), a saber: el uso transitorio, la extracción de texto y datos, la excepción de críticas y/o revisión y de seguridad pública. En el apartado 6, el artículo argumenta que este tipo de noticias podría y debería ser despojado de los derechos de autor por motivos de interés público. Finalmente, se exponen las conclusiones en el apartado 7. Al considerar las cuestiones legales y políticas que se plantean en este artículo, se tendrán en cuenta diferentes jurisdicciones, especialmente los EE. UU., El Reino Unido y la Unión Europea (UE).

\section{El concepto y la naturaleza de las noticias falsas}

Las noticias falsas se pueden crear y compartir de formas muy diferentes. Pueden tomar la forma de obras literarias (por ejemplo, artículos de periódicos, twits, publicaciones de blogs, etc.), imágenes o videos. Pero ¿se puede dar una definición precisa? ¿Existe un criterio que pueda guiar a abogados, académicos, legisladores y plataformas para determinar de manera consistente en qué consiste es este fenómeno?

Según el Grupo de Expertos de Alto Nivel de la UE sobre noticias falsas y desinformación en línea (HLEG), el término "desinformación" es más adecuado que el de "noticias falsas" por al menos dos razones: (1) el problema no se limita específicamente a las noticias, sino que cubre la difusión de información falsa o engañosa de manera más general, incluso a través de cuentas falsas, videos y otros medios de publicidad u otras operaciones de información organizada; y (2) los políticos han adoptado el término "noticias falsas" para criticar la información que va en contra de sus intereses (European Commission, 2018, p. 10). El HLEG define la desinformación como "información falsa, inexacta o engañosa diseñada, presentada y promovida para causar intencionalmente daño público o con fines de lucro" y agrega que el riesgo de daño incluye "amenazas a los pro- 
cesos y valores políticos democráticos, que pueden dirigirse específicamente a una variedad de sectores, como salud, ciencia, educación, finanzas y más” (European Commission, 2018). El HLEG también distingue la noción de desinformación de la de misinformation, es decir, "información engañosa o inexacta compartida por personas que no la reconocen como tal" (European Commission, 2018), y excluye de la noción de "desinformación" todas las cuestiones relacionadas con formas ilegales de expresión, como la incitación al odio o a la violencia, etc., así como la parodia. Si bien concordamos con que la noción de "desinformación" es un término más preciso que "noticias falsas", usaremos predominantemente este último a lo largo de este artículo.

Una forma posible de conceptualizar algunas distinciones importantes entre los diferentes tipos de información manipuladora y problemática es adoptar un enfoque analítico de las noticias falsas y la desinformación, centrándose en tres parámetros: (i) la veracidad fáctica del contenido; (ii) la intención y los objetivos estratégicos asociados con la generación y el intercambio inicial del contenido; y (iii) el daño causado por la divulgación del contenido a la esfera pública. Si bien cada uno de estos factores es difícil de determinar en la práctica y depender demasiado de cualquiera de ellos puede proporcionar una base poco sólida, es posible desarrollar una taxonomía amplia a través de estos tres factores. La presencia de algún daño junto con cierto nivel de inexactitud fáctica plantea problemas regulatorios, que a veces pueden abordarse satisfactoriamente a través de las leyes existentes (por ejemplo, leyes de difamación). Sin embargo, existe la necesidad de recursos legales y reglamentarios ad hoc efectivos en los que la inexactitud de los hechos y el daño se combinen con el objetivo preordenado de manipular, elaborar/generar y propagar información falsa o engañosa. Como se mencionó, se han introducido algunas leyes recientemente a nivel nacional para contrarrestar este fenómeno y queda por ver si estas cumplen el objetivo para el que fueron diseñadas.

Recientemente se ha propuesto una taxonomía autorizada de noticias falsas, con varias categorías identificadas que incluyen: (a) sátira; (b) fabricación; (c) manipulación; (d) propaganda; y (e) contenido falso de conexión (Tandoc et al., 2018; Zannettou et al., 2019;). 
La característica común de estas categorías es la determinación de los creadores de representar estas formas de noticias falsas como reales y, en última instancia, engañar al público. (a) La sátira se utiliza para presentar contenido falso bajo una perspectiva humorística. Si bien generalmente lo realizan comediantes con el propósito real de entretener a la opinión pública, existe el riesgo de que la gente pueda confundir la sátira con noticias reales (Tandoc et al., 2018, p. 141). b) La producción/elaboración de noticias se refiere a contenidos "que no tienen una base fáctica, pero que se publican al estilo de los artículos de noticias para crear legitimidad" ( Tandoc et al., 2018, p. 143) y con la intención específica de engañar a la audiencia. Este tipo de contenido suele ser creado por grupos partidistas y publicado en sitios web, blogs o plataformas de redes sociales, intentando imitar medios creíbles a través de la "apariencia de objetividad y reportajes equilibrados” (Tandoc et al., 2018, p. 143). Esta categoría generalmente se refiere a elementos basados en el texto. (c) El contenido manipulado se define como la "manipulación de imágenes o videos reales para crear una narrativa falsa" (Tandoc et al., 2018, p. 144) o para tergiversar la realidad. Existen varias técnicas y métodos de manipulación de noticias visuales: con la llegada de las fotos digitales y el poderoso software de manipulación de imágenes, es posible agregar, eliminar o alterar las características originales para llamar la atención de la audiencia. (d) La propaganda incluye historias inventadas "que tienen como objetivo dańar los intereses de un partido en particular y generalmente tienen un contexto político" (Zannettou et al., 2019, pp. 10-14). (e) Por último, se produce un contexto falso de conexión cuando el contenido válido se combina con contenido falso; un ejemplo de ello es el título de una noticia que no refleja el contenido proporcionado en el artículo (House of Commons, 2018, p. 7). En el apartado de este artículo que se centra en el análisis de los derechos de autor, proporcionaremos ejemplos de noticias falsas que pueden considerarse producción/elaboración, contenido manipulado y propaganda.

Las noticias falsas se canalizan predominantemente a través de plataformas web, mostrando deliberadamente contenido falso con el fin de imitar noticias ordinarias de importancia generalizada. Pueden publicarse por motivos políticos o simplemente para trolling. 
Sin embargo, como se mencionó, a menudo existe también un propósito de lucro (Braun y Ecklund, 2019). Los editores de estas noticias pueden ganar mucho dinero con campańas publicitarias y de marketing que generan una gran cantidad de tráfico. El modelo de negocio de noticias falsas utiliza con frecuencia Facebook y otras plataformas de redes sociales (así como cientos de otras redes publicitarias) para aumentar el tiempo que las audiencias pasan leyendo esas noticias. El sistema frecuentemente crea una estructura de incentivos lucrativa tanto para los creadores como para los editores (Braun y Ecklund, 2019, pp. 7-8). Esto también significa que "cuanto más ampliamente se pueda difundir una desinformación, mayores serán las posibilidades de que capture la imaginación del público y logre su objetivo, ya sea desacreditar a un oponente, sembrar discordia o generar ganancias" (Digital Shadows, 2017, s.p.).

El sistema suele funcionar de la siguiente manera (Haenschen y Ellenbogen, 2016). Una persona publica información falsa en un sitio web y luego le paga a una red publicitaria para anunciar un enlace a la publicación. Por tanto, la red se beneficia de la publicidad en su plataforma, generando lucro en función del número de personas que hacen clic en el enlace y/o ven los anuncios. Los usuarios de las redes sociales hacen clic en los enlaces anunciados y visitan el sitio web de noticias falsas, lo que genera una impresión para cada anuncio gráfico en el sitio. El sitio web obtiene ingresos de las impresiones publicitarias resultantes, que pueden ascender a millones de páginas vistas y decenas de miles de dólares por mes (Haenschen y Ellenbogen, 2016). El modelo de negocio de las redes sociales se basa esencialmente en el compromiso, la interacción, la creación y el consumo de contenido por parte de los usuarios (Kshetri y Voas, 2017, p. 10), lo que significa que cuantos más usuarios lean, hagan clic, compartan e interactúen con el contenido, más beneficios obtendrá la plataforma (Kshetri y Voas, 2017). Como resultado, las plataformas de redes sociales a menudo no prestan mucha atención a la fuente o veracidad de la información (Solon, 2016). 


\section{Lucha contra la desinformación: enfoques divergentes entre la UE y los EE. UU.}

Como se mencionó anteriormente, las noticias falsas han sido un desafío serio para muchos países, llegando a convertirse en problemas de seguridad nacional. Es también por ello que varios países comenzaron a establecer reglas destinadas a frenar este fenómeno. Sin embargo, regular las noticias falsas, especialmente en línea, no es una tarea fácil. En general, en casi todos los sistemas democráticos el uso de formas nuevas y tradicionales de medios de información no solo ha planteado problemas de definición de límites, sino que a menudo también ha dado lugar a intentos de contener y controlar el flujo de información (Castells, 2010, p. 320; Couch, 1990, p. 111). La experiencia de los países democráticos con disposiciones diseñadas para monitorear y controlar el flujo de información revela que restringir la libertad de los medios de comunicación puede no resistir el escrutinio constitucional. Muchos instrumentos regulatorios implementados en varios países durante la última década para vigilar los medios digitales han sido con frecuencia criticados por su incapacidad para conciliar el progreso tecnológico, la protección de los intereses económicos y otros intereses en conflicto. ${ }^{2}$ Los problemas regulatorios y los posibles planes de acción contra las noticias falsas se vuelven aún más complejos por las diferencias nacionales en las garantías constitucionales, las inmunidades de las plataformas y las obligaciones de monitoreo. Estos aspectos también han contribuido a la divergencia de enfoques entre países, especialmente entre Europa y los Estados Unidos.

Cabe recordar de manera preliminar que en los últimos sesenta

2 Los ejemplos incluyen: la controversia sobre la constitucionalidad de la Ley de Decencia de las Comunicaciones de los Estados Unidos de 1996 en Reno v. American Civil Liberties Union (que invalida ciertas disposiciones de una propuesta de ley diseñada para regular el discurso indecente y obsceno en internet), ver 521 US 844 (1997); y el caso francés Loi Fillon: véase la decisión núm. 96-378 DC, 23 de julio de 1996, Journal Officiel de la République Française [JO] [Gaceta Oficial de Francia], 27 de julio de 1996, en 11400 (Fr.) (censurando la mayoría de las disposiciones de la enmienda Fillon sobre la regulación de internet y el poder otorgado al Conseil Supérieur de l'Audiovisuel [Autoridad Reguladora Audiovisual]). 
años las leyes que regulan la libertad de expresión en Europa han evolucionado de manera diferente a como se han desarrollado en los Estados Unidos. Mientras que en este país los tribunales a menudo han suavizado las restricciones sobre la capacidad de los medios de publicar información inexacta, en Europa los tribunales han seguido un enfoque más cauteloso que se centra en el valor de la dignidad humana y el pluralismo. Como resultado, la regulación de la libertad de expresión en línea y las noticias falsas puede encontrar más resistencia en los Estados Unidos que en Europa. De hecho, el derecho de la prensa y de los oradores a comunicarse libremente está tan fuertemente protegido en Estados Unidos que hace que la desinformación sea difícil de contrarrestar. El modelo de protección de "libre mercado de ideas" estadounidense no encaja fácilmente en el contexto europeo. Esto queda claro al comparar la redacción de la Primera Enmienda de la Constitución de los Estados Unidos con el artículo 10 del Convenio Europeo de Derechos Humanos (CEDH), ${ }^{3}$ que pone énfasis en los límites de la libertad de expresión y rechaza la visión de esta como un derecho absoluto. ${ }^{4}$ Por lo tanto, puede ser más fácil luchar contra las noticias falsas en Europa que en los EE. UU.

Además, mientras que la Primera Enmienda de la Constitución de los Estados Unidos aborda principalmente la dimensión activa del discurso, es decir, el derecho del orador a impartir información libremente, el CEDH (artículo 10) y la Carta de los Derechos Fundamentales de la UE (artículo 11) enfatizan su dimensión pasiva, es decir, el dere-

3 Convention for the Protection of Human Rights and Fundamental Freedoms, opened for signature Nov. 4, 1950, 213 U.N.T.S. 221, Europ. T.S. No. 5.

4 Para un comentario sobre el arte. 10 ECHR, ver Flauss (2009). Como es sabido, la estructura del artículo 10 del CEDH es doble: el artículo 10 (1) otorga a la libertad de expresión un estatuto de derecho humano, mientras que el artículo 10 (2) justifica las interferencias en la libertad de expresión que son necesarias, en una sociedad democrática, para cumplir ciertas necesidades sociales urgentes. En otras palabras, los Estados contratantes del CEDH pueden imponer legítimamente restricciones a la libertad de expresión, siempre que los criterios establecidos en el artículo se respeten 10 (2). Solo en un número limitado de casos, el Tribunal Europeo de Derechos Humanos llegó a la conclusión de que no se cumplía la condición "prescrita por la ley". Esta condición requiere previsibilidad, precisión, publicidad o accesibilidad de la restricción (ver Voorhoof, 2009). 
cho de la audiencia a estar informada y a recibir información de forma pluralista. A este respecto, se podría argumentar que las noticias falsas y la información engañosa o falsa no entran en el ámbito de la protección europea de la libertad de expresión. Los tribunales europeos, por ejemplo, nunca seguirían el enfoque adoptado por la Corte Suprema de Estados Unidos en Gertz, donde se sostuvo que "[bajo] la Primera Enmienda no existen las ideas falsas. Por perniciosa que pueda parecer una opinión, dependemos para su corrección [...] de la competencia de otras ideas". ${ }^{5}$ El Tribunal Europeo de Derechos Humanos (TEDH), el guardián del $\mathrm{TEDH}$, sigue un enfoque diferente, especialmente cuando se trata de información canalizada a través de internet. La premisa detrás de su razonamiento es que la web plantea nuevos desafíos para la protección de los derechos fundamentales y que las medidas que regulan los medios tradicionales no funcionan de manera efectiva en el entorno digital; por ello es que debe buscarse un nuevo equilibrio entre la libertad de expresión y otros derechos humanos en conflicto, que con frecuencia se inclina a favor de más restricciones a la libertad de expresión. Por lo tanto, el enfoque del TEDH se opone al seguido por la Corte Suprema de los Estados Unidos. En Reno v. $A C L U,{ }^{6}$ se sostuvo que [como] una cuestión de tradición constitucional, en ausencia de evidencia en sentido contrario, presumimos que la regulación gubernamental del contenido del discurso tiene más probabilidades de interferir con el libre intercambio de ideas que de alentarlo. El interés en promover la libertad de expresión en una sociedad democrática supera cualquier beneficio teórico - pero no demostrado- de la censura. ${ }^{7}$

Otro elemento complejo en el marco regulatorio para abordar la desinformación radica en los diferentes tipos de inmunidad de los intermediarios de internet adoptados en los EE. UU. y en Europa. En los Estados Unidos, estos intermediarios tienen una gran libertad. La Ley de Decencia en las Comunicaciones (CDA $)^{8}$ confiere total inmunidad a los "servicios informáticos interactivos" para distribuir cualquier contenido compartido utilizando sus servicios,

5 Gertz, 418 U.S. 323 (1974), pp. 339-340.

6521 US 844, 885 .

7521 US 844, 885 .

$8 \quad 47$ U.S.C. \$230. 
estableciendo que "ningún proveedor o usuario de un servicio informático interactivo será tratado como editor o relator de ninguna información proporcionada por otro proveedor de contenido de información". ' En otras palabras, los "servicios informáticos interactivos" no deben ser tratados como editores responsables del contenido que se publica, sino como intermediarios pasivos que canalizan las comunicaciones y, en consecuencia, no tienen responsabilidad por el contenido que se comunica. Esta inmunidad es particularmente fuerte, ya que se aplica incluso si el intermediario conoce el contenido difamatorio de su servicio y, a sabiendas, no lo elimina (Lavi, 2017, p. 164). Por lo tanto, considerar a los intermediarios de internet responsables de las noticias falsas canalizadas a través de sus plataformas puede ser difícil en EE. UU.

Por el contrario, en la UE los intermediarios se benefician de la inmunidad solo mientras sigan siendo facilitadores pasivos e inconscientes. Se les exige que eliminen el contenido ilegal una vez que sepan de su presencia en su servicio, por ejemplo, cuando un usuario les notifica. Además, en Google France v. Louis Vuitton, ${ }^{10}$ un caso sobre responsabilidad de los proveedores de servicios de internet por infracción de marca, el Tribunal de Justicia de la Unión Europea (TJUE) declaró que la Directiva de comercio electrónico, que otorga inmunidad a los proveedores de alojamiento, solo se aplica si el almacenamiento de contenido es "de carácter meramente técnico, automático y pasivo" 11 y si la entidad no desempeña "un papel activo de tal naturaleza que le otorgue conocimiento o control sobre los datos almacenados". ${ }^{12}$ Sin embargo, el hecho de que los intermediarios de internet puedan ser inmunes a la responsabilidad del contenido en estas circunstancias no significa que no tengan obligaciones con respecto al contenido que ponen a disposición. Surge una variedad

9 Vale la pena señalar que en $\$ 230$ (f) (3) "proveedor de contenido de información" se define como "cualquier persona o entidad que sea responsable, total o parcialmente, de la creación o desarrollo de información proporcionada a través de Internet o cualquier otro servicio informático".

10 C-236/08, C-237/08 y C-238/08 Google France Sarl v. Louis Vuitton Malletier $S A$ [2010] ECR I-2417.

11 Ídem, $\$ 113-114$.

12 Ídem, \$ 120. 
de obligaciones con el fin de monitorear y controlar el contenido, por ejemplo, bajo el Reglamento General de Protección de Datos de la UE (GDPR), ${ }^{13}$ que introduce ciertas obligaciones de los intermediarios en relación con contenido policial. Por tanto, no se puede descartar que en un entorno tan regulatorio se materialice pronto en un escenario en el que los intermediarios de internet sean responsables de las fake news que se difunden a través de sus plataformas. ${ }^{14}$

Si bien en los EE. UU. cualquier regulación de la libertad de expresión, como hemos visto, es difícil de implementar debido a las limitaciones derivadas de la Primera Enmienda, la UE lanzó una serie de acciones para verificar la viabilidad de una intervención legislativa destinada a limitar la difusión de contenido falso, ${ }^{15}$ y Alemania y Francia ya han introducido leyes específicas (Pitruzzella y Pollicino, 2020, pp. 97-130). Entre las medidas adoptadas por la UE cabe mencionar: la creación en enero de 2018 del Grupo de Expertos de Alto Nivel, antes mencionado, para desarrollar una estrategia de la UE; incluye cuarenta representantes de plataformas de redes sociales y organizaciones de medios, del mundo académico y del periodismo, así como miembros de la sociedad civil (European Commission, 2018); el Código de Práctica sobre Desinformación, acordado por representantes de plataformas online, redes sociales líderes e industria de la publicidad, todos comprometidos de forma voluntaria a adoptar un conjunto de estándares para contrarrestar las prácticas de desinformación en diferentes ámbitos; ${ }^{16}$ la implementación de un Plan de Acción para intensificar los esfuerzos para contrarrestar la

13 Reglamento (UE) 2016/679 (Reglamento general de protección de datos) OJ L 119, 04.05.2016.

14 A nivel de la UE ya existen normas sectoriales, vease e.g. la Directiva 2010/13 / UE del Parlamento Europeo y del Consejo, de 10 de marzo de 2010, sobre la coordinación de disposiciones legales, reglamentarias y administrativas de los Estados miembros relativos a la prestación de servicios de comunicación audiovisual (Directiva de servicios de comunicación audiovisual).

15 Recomendación (UE) 2018/334 de la Comisión de la UE, de 1 de marzo de 2018, sobre medidas para abordar eficazmente los contenidos ilícitos en línea C/2018/1177, OJ L 63, 6.3.2018.

16 El Código va acompańado de un anexo que establece un conjunto de mejores prácticas. Véase la página web https://ec.europa.eu/digital-single-market/en/ news/code-practice-disinformation. 
desinformación en Europa (European Commission \& High Representative of the Union for Foreign Affairs and Security Policy, 2018).

\section{Noticias falsas: contenido protegido por derechos de autor y originalidad}

En este apartado nos centraremos en la cuestión de si las noticias falsas serían protegibles en virtud de los derechos de autor y si cumplirían con los requisitos pertinentes, especialmente el de la originalidad. El análisis no comprende las cuestiones relacionadas con la naturaleza ilegal de este tema, que se abordarán en el siguiente apartado. Con este fin, consideraremos el enfoque de diferentes jurisdicciones, especialmente los EE. UU., El Reino Unido y la Unión Europea (UE). En particular, se intentará identificar temas que sean capaces de estimular la discusión académica y la contaminación de enfoques jurídicos entre los diferentes ordenamientos jurídicos, con el objetivo de promover intercambios y diálogos entre legisladores, jueces y estudiosos del derecho.

Como observación general, las noticias (y los hechos) per se quedan excluidos de la tutela del derecho de autor. ${ }^{17}$ El principio está consagrado en la legislación internacional, ya que en particular el Convenio de Berna no ofrece protección a las "noticias del día" o a los "hechos que constituyan mera información de prensa" (Slauter, 2019, p. 170). ${ }^{18}$ Esto significa que, por ejemplo, la mera noticia en noviembre de 2020 de que Joe Biden fue elegido como el $46^{\circ}$ presidente de los Estados Unidos y que Donald Trump no admitió tal derrota debido a alegaciones -sin fundamento- de supuesto fraude no puede ser protegida por derechos de autor. La razón de esto es clara: se trata de un simple hecho. Es necesario evitar la monopolización de meros hechos y la atribución de derechos exclusivos sobre estos a una sola entidad. Esto no significa que los artículos de revistas que han dado ese anuncio o comentado sobre tales noticias no

17 En lo que respecta a la legislación estadounidense, véase Feist Publications, Inc. v. Rural Telephone Service Co., Inc., 499 U.S. 340, 111 S. Ct. 1282 (1991).

18 Artículo 2 (8) del Convenio de Berna para la Protección de Obras Literarias y Artísticas. 
sean susceptibles de derechos de autor: de hecho, dichos artículos constituyen una forma de expresar (y comentar) esos hechos y, por lo tanto, pueden protegerse como obras literarias. Este principio fue confirmado, además, en el antiguo caso del Reino Unido Walter $v$. Steinkopff, ${ }^{19}$ una disputa sobre la copia periodística en la que North J. reconoció la subsistencia de derechos de autor en artículos de noticias, señalando, además, que los derechos de autor no protegen la sustancia de las noticias, sino su forma (Slauter, 2019, p. 176). Para facilitar nuestra referencia en este documento, seguiremos denominando a estos artículos "noticias", aunque técnicamente son "narraciones de noticias".

La cuestión de si las noticias deben estar protegidas por derechos de autor se ha revitalizado más recientemente por la proliferación de agregadores de noticias, es decir, entidades que recopilan artículos de periódicos en línea en un lugar para que las personas puedan verlos fácilmente. $^{20}$

Si bien es posible argumentar que considerar las noticias como protegidas por derechos de autor y permitir que los editores hagan valer este derecho puede, en algunas circunstancias, ser similar a monopolizar la información básica, el movimiento reciente de la legislatura de la UE parece ir en la dirección opuesta. Como es sabido, la Directiva de 2019 sobre derechos de autor en el mercado único digital (DSM) ha introducido el ampliamente discutido "derecho de los editores" (Bently, 2016), el cual ha sido fuertemente cabildeado por la industria editorial y le permite a la prensa beneficiarse durante dos años de parte de las ganancias que perciben los agregadores de noticias y las redes sociales cuando recuperan y/o ponen a disposición de los consumidores sus publicaciones (es básicamente un derecho de regalía ofrecido a editores). ${ }^{21} \mathrm{Si}$ bien la Directiva DSM especifica que el nuevo derecho no se aplica al uso de "extractos muy breves",

19 Walter v. Steinkopff [1892] 3 Ch 489 (con North J. encontrando que los periódicos no tenían licencia implícita para copiar los informes textuales que se publicaron en otros periódicos).

20 Sobre el éxito de los agregadores de noticias, véase https://www.tse-fr.eu/ sites/default/files/TSE/documents/doc/wp/2018/wp_tse_912.pdf.

21 Art. 15 Directiva (UE) 2019/790 del Parlamento Europeo y del Consejo, de 17 de abril de 2019, sobre derechos de autor y derechos afines en el mercado 
el significado y el alcance exacto de dicha exención están lejos de ser claros (¿qué tan corto debe ser exentado?). Es por este motivo que tal protección ha dado lugar a críticas (Karapapa, 2018, p. 316). En particular, si la expresión "extractos muy breves" se interpretara de manera demasiado restringida, se teme que el derecho pueda constituir un obstáculo para la difusión de meros hechos, contraviniendo así el principio (antes mencionado y) fundamental del derecho de autor, es decir, que lo que se protege no es un hecho, sino la forma en que se expresa. ${ }^{22}$

La introducción de este nuevo derecho no es una gran sorpresa. Por ejemplo, que los titulares y los extractos de noticias puedan estar amparados por derechos de autor ya había sido confirmado en el Reino Unido por el Tribunal Superior y el Tribunal de Apelación en Newspaper Licensing Agency v. Meltwater Holding, en el que se declaró que los extractos de periódicos son susceptibles de derechos de autor y que los usuarios de los servicios de monitoreo de medios en línea violan los derechos de autor de los editores a menos que obtengan una licencia. ${ }^{23}$ También debe recordarse que en algunos países, especialmente en los Estados Unidos, los editores históricamente han presionado y obtenido alguna forma de protección de los hechos en los que se basan sus artículos de noticias. En un asunto ilustrador de 1918,

único digital y que modifica las Directivas 96/9/ CE y 2001/29/CE.

22 Sin embargo, este principio no ha impedido la introducción de reglas que protejan los hechos a través de un régimen (cuasi) de derechos de autor. La Directiva sobre bases de datos de la UE de 1996 hace exactamente eso, ya que ofrece a las bases de datos no creativas un derecho sui generis que protege principalmente las inversiones en la obtención, verificación y presentación de datos. La introducción de este derecho ha sido criticada, también fuera de la UE (Boyle, 2008, pp. 208-220).

23 Newspaper Licensing Agency Ltd. and others v. Meltwater Holding BV and others [2010] EWHC 3099 (Ch); The Newspaper Licensing Agency and others $v$. Meltwater Holding BV and others [2011] EWCA Civ 890. El TJUE también confirmó en Infopaq que las obras literarias muy breves pueden estar protegidas por derechos de autor, en el que se sostuvo que la reproducción de un extracto de una obra protegida de 11 palabras equivale a una infracción de los derechos de autor (Case C-5/08, Infopaq Int'l A/S v. Danske Dagblades Forening, 2009 E.C.R I-6569). 
International News Service v. Associated Press, ${ }^{24}$ la Corte Suprema de los Estados Unidos afirmó la aplicación de apropiación indebida para brindar protección a los recolectores de noticias respecto a los competidores que se aprovechaban libremente de sus esfuerzos e inversiones en activos intangibles, incluida la información. Más específicamente, el Tribunal reconoció ciertos derechos exclusivos sobre los detalles fácticos (comercialmente valiosos) de las noticias después de su publicación con el objetivo de contrarrestar la competencia desleal. Después de que esta doctrina cayera en desuso, varias jurisdicciones de leyes estatales de EE. UU. restablecieron, desarrollaron y reposicionaron sus leyes de competencia desleal (Balganesh, 2011).

Dicho esto, ¿qué ocurre con el tema que se aborda en este artículo, es decir, noticias falsas difundidas a través de internet y las redes sociales? Aquí se podría argumentar que debido a que tales noticias están "producidas y elaboradas creativamente", no solo caerían dentro del alcance de la materia sujeta del derecho de autor, sino que también cumplirían con el requisito de originalidad. De hecho, la protección o no de las formas de creatividad depende de si la obra alcanza un nivel suficiente de originalidad. Aunque el Convenio de Berna no establece explícitamente que las obras protegidas por derechos de autor deban ser "originales", la mayoría de los países sí lo establecen. La prueba de originalidad varía de una jurisdicción a otra: en la prueba de originalidad, según la ley de EE. UU. (como se afirmó en Feist v. Rural); $;^{25}$ el criterio de "creación intelectual" de la UE, según Infopaq; ${ }^{26}$ u otros requisitos de originalidad, como el estándar de "habilidad, trabajo y juicio" del Reino Unido. ${ }^{27}$ De hecho,

\section{International News Service v. Associated Press (248 U.S. 215).}

25 Véase nuevamente Feist Publications, Inc. v. Rural Telephone Service Co., Inc., 499 U.S. 340, 111 S. Ct. 1282 (1991). En este caso, la Corte Suprema de los Estados Unidos explicó que el requisito de originalidad se compone de dos elementos: que la obra sea creada de forma independiente por el autor (a diferencia de la copia de otras obras) y que posea al menos algún grado mínimo de creatividad.

26 Véase el Caso C-5/08, Infopaq Int'l A / S contra Danske Dagblades Forening, 2009 E.C.R I-6569 (que establece el estándar de originalidad de la UE para la protección de los derechos de autor).

27 Véase, por ejemplo, Ladbroke v. William Hill [1964] 1 All E.R. 465, 469 
las noticias falsas equivalen a una historia inventada y no basada en hechos (Humphrey, 2017, p. 141) y, por lo tanto, son tan creativas y originales como la ficción, aunque no se presenten como tales al público (Smith, 2019, p. 213).

Se podría hacer una analogía con el caso Nash v. CBS de 1990 en los Estados Unidos, ${ }^{28}$ que trató la cuestión de si un libro basado en hechos falsos puede estar protegido por derechos de autor. Jay Robert Nash escribió dos libros sobre John Dillinger, un gánster estadounidense de la época de la Gran Depresión, argumentando que no había sido asesinado por el FBI como todos pensaban, sino que estaba vivo y que había sobrevivido a una operación de esa agencia gubernamental. Después de que el acusado -CBS- transmitiera un programa que incorporaba las afirmaciones de Nash sobre Dillinger, el primero presentó una demanda por infracción de derechos de autor. Aunque la corte (el Séptimo Circuito) declaró que los derechos de autor no se extendían a los eventos históricos en sí mismos, concluyó que sí subsistían en la presentación y exposición de Nash de esos eventos. Si bien el tipo de obra en Nash v. CBS es diferente del tema en el que nos enfocamos aquí (es decir, noticias falsas difundidas predominantemente a través de internet y las redes sociales), la cuestión planteada por el tribunal puede usarse para respaldar el argumento de que la falsificación moderna de noticias, en particular la forma en que se narran (creativamente) los eventos subyacentes, están protegidas contra la copia, especialmente la copia literal (Copyright Alliance, 2017).

En este contexto, en el presente apartado se analizan tres noticias falsas relativamente recientes que se han difundido ampliamente en línea y que han atraído la atención de los medios internacionales, como así también del público, ello a los fines de verificar si dichas

(Eng.). Esta es la forma en la que tradicionalmente se ha interpretado el requisito de originalidad en el Reino Unido. Se ha observado que, incluso después de Infopaq, la prueba de "habilidad, trabajo y juicio" puede sobrevivir y coexistir con la prueba de "creación intelectual" desarrollada bajo la ley de la UE (Rahmatian, 2013). Queda por ver si el antiguo estándar del Reino Unido volverá a predominar en la era posterior al Brexit (Bently et al., 2018, p. 102).

28 Nash v. CBS, Inc., United States Court of Appeals for the Seventh Circuit 899 F.2d 1537 (1990). 
noticias pueden ser susceptibles de derechos de autor. El primer ejemplo es un artículo breve, mientras que los otros dos ejemplos se refieren a una fotografía modificada digitalmente y a un video manipulado. Dichos casos han sido seleccionados con el propósito de identificar tendencias, resaltar posibles puntos en común y/o diferencias en la expansión sin restricciones de las noticias falsas y/o de la desinformación. Nos hemos centrado en escenarios que consideramos (personifican) materializan/ilustran ampliamente los principales problemas de derechos de autor que plantean las diversas categorías de desinformación. Como se mencionó, las fotos y videos se incluyen dentro del perímetro de análisis de este apartado, aunque en rigor muchas veces deben ser considerados como contenidos adicionales que prestan emoción y aparente legitimidad a la parte escrita de las historias falsas, contribuyendo a impulsar su crecimiento (Mallonee, 2016). Las imágenes son también importantes, ya que a menudo se combinan con el texto de las noticias para engañar a los lectores y sus creadores son conscientes de que las personas tienden a aceptar imágenes o videos como veraz, porque "la gente cree lo que ve y ve lo que cree" (Mallonee, 2016). De esta forma, las imágenes pueden reforzar los prejuicios existentes (Mallonee, 2016).

\subsection{Las noticias sobre el apoyo del papa Francisco a la presidencia de Donald Trump}

En el período previo a las elecciones presidenciales de EE. UU. de 2016, un breve artículo titulado "El Papa Francisco conmociona al mundo, respalda a Donald Trump como presidente" hace pública una declaración que se difundió ampliamente en internet y en las redes sociales. ${ }^{29} \mathrm{El}$ artículo comienza afirmando que los medios de comunicación de todo el mundo informaban sobre la noticia de que el papa Francisco había tomado la decisión de apoyar a Donald Trump en la carrera hacia la presidencia, incorporando también una declaración (falsa) del Vaticano que incluía las siguientes oraciones:

I have been hesitant to offer any kind of support for either candidate

29 La noticia se puede leer en https://web.archive.org/web/20161115024211/ 
in the US presidential election but I now feel that to not voice my concern would be a dereliction of my duty as the Holy See. [...] The FBI, in refusing to recommend prosecution after admitting that the law had been broken on multiple occasions by Secretary Clinton, has exposed itself as corrupted by political forces that have become far too powerful. Though I don't agree with Mr. Trump on some issues, I feel that voting against the powerful political forces that have corrupted the entire American federal government is the only option for a nation that desires a government that is truly for the people and by the people. For this primary reason I ask, not as the Holy Father, but as a concerned citizen of the world that Americans vote for Donald Trump for President of the United States.

El breve artículo también hace referencia a que fuentes dentro del Vaticano sabían que el papa había tenido en cuenta la idea de hacer pública su preocupación por las elecciones estadounidenses, pero que estas fuentes aparentemente habían quedado totalmente en la oscuridad hasta que se publicó la declaración anterior.

Este es un ejemplo típico y de manual de noticias falsas. Entonces ¿qué sucede con los derechos de autor? ¿Se podría proteger esta noticia como obra literaria?, una obra dramática o musical, que esté escrita, hablada o cantada (esta es la definición dada por la Ley de Derechos de Autor del Reino Unido). ${ }^{30}$ La Oficina de Derechos de Autor de EE. UU. aclara que una obra literaria es "una obra que explica, describe o narra un tema, idea en particular mediante el uso de texto narrativo, descriptivo o explicativo [...] En general, las obras literarias están destinadas a ser leídas”. La historia del papa Francisco se inscribe claramente en estas definiciones. La noticia también se fija en un medio tangible (como es sabido, la fijación es un requisito de protección en varias jurisdicciones, incluidos el Reino Unido y los EE. UU.) y pareciera satisfacer el requisito de originalidad. Incluso se puede decir: ¡es muy original, ya que la historia es totalmente ficticia!

http://wtoe5news.com/us-election/pope-francis-shocks-world-endorsesdonald-trump-for-president-release-statement.

30 Sec. 3(1) of the UK Copyright, Designs, Patents Act (CDPA). 


\subsection{La fotografía modificada digitalmente de Angela Merkel en Arabia Saudita}

En mayo de 2017, la canciller alemana estuvo en el centro de las noticias por ser una de las mujeres políticas que había optado por no llevar pańuelo en la cabeza cuando visitaba un país árabe. Una foto que la muestra durante su visita de Estado a Arabia Saudita se difundió ampliamente en internet y en las redes sociales. La foto fue modificada digitalmente (sus cabellos estaban borrosos) para enviar el mensaje de que la televisión estatal de ese país (la foto fue tomada de ese metraje de televisión) no quería mostrar la cabeza de Merkel sin el pañuelo en la cabeza.

La fotografía modificada es claramente falsa (Bartlett, 2020). ¿Podría estar protegida por derechos de autor? Se puede argumentar que la intervención digital ha transformado la fotografía en sí, convirtiéndola en una obra derivada original (y fija), que atrae un nuevo derecho de autor, una nueva obra que es independiente de los derechos que protegen la fotografía original. Considerando, por ejemplo, en el hipotético caso de que un sujeto sea acusado de haber copiado y de haberse beneficiado de la foto falsa, este intentaría alegar que la modificación digital, es decir, difuminar los cabellos de Angela Merkel, es una alteración menor que no cambia sustancialmente la imagen original y que, por lo tanto, la imagen falsa no es una obra original que merezca protección de derechos de autor; por lo tanto, la reproducción y explotación de la foto modificada no constituiría una infracción de un derecho de autor "no existente". Es difícil predecir cómo se resolvería esta disputa imaginaria, ya que la decisión final también depende de varios factores, como la valoración subjetiva que realizan los jueces en diferentes países. Según la legislación de la UE, por ejemplo, la cuestión dependería de si el juez considera que la modificación digital de la imagen en cuestión constituye una "creación intelectual" según el criterio adoptado en la decisión Infopaq del Tribunal de Justicia de la Unión Europea, ${ }^{31}$

31 Infopaq Int'l A/S v. Danske Dagblades Forening, 2009 E.C.R I-6569 (según esta decisión, se consideran originales las creaciones que sean propias de su autor por reflejar su personalidad, siendo este reflejo de la personalidad verificado de conformidad con el criterio estándar del test de la libre elección del autor). 
mientras que en el Reino Unido es probable que el tribunal deba convencerse de que la alteración implica suficiente "habilidad, trabajo y juicio". ${ }^{32}$ En Estados Unidos, la atención se centraría en si la alteración de la fotografía implica un mínimo de creatividad. ${ }^{33}$

También debemos tener en cuenta que el creador de la imagen falsa de Angela Merkel usó y modificó una imagen creada previamente (tomada de la televisión estatal de Arabia Saudita). Esto plantea la cuestión de si se infringen los derechos de autor sobre dicha imagen. Sin embargo, la transformación digital de la imagen podría eximir al creador de la fotografía falsa de responsabilidad, especialmente en países como los EE. UU., donde los tribunales a menudo han avalado el "uso justo/legítimo transformador" (en Europa, las posibilidades de prevalecer en un caso de uso transformador serían más reducidas). En Cariou v. Prince, ${ }^{34}$ por ejemplo, la Corte de Apelaciones de EE. UU. sostuvo que la apropiación del artista Richard Prince (y una ligera modificación digital) de las fotografías de Patrick Cariou de los rastafaris jamaicanos era un uso legítimo y que varias de sus obras eran usos legítimos transformadores de imágenes de Cariou. Por lo tanto, la decisión de si el uso y adaptación de una fotografía falsa que se apropia de una imagen anterior constituye una infracción de derechos de autor dependerá de la jurisdicción donde se instaure la acción judicial y, en particular, de los hechos de cada caso, como también del análisis subjetivo que realicen los jueces de dichos hechos. En tal sentido, es bien sabido que los casos de fair use y fair dealing son a menudo impredecibles, específicos de hechos y con frecuencia dan lugar a decisiones contradictorias.

\subsection{El video de los delfines de Venecia}

A principios de marzo de 2020, Italia fue el primer país que entró en confinamiento total debido al brote de COVID-19. Un video (apa-

32 Véase el Caso C-5/08, Infopaq Int'l A / S contra Danske Dagblades Forening, 2009 E.C.R I-6569.

33 Feist Publications, Inc. v. Rural Telephone Service Co., Inc., 499 U.S. 340, 111 S. Ct. 1282 (1991).

34 Cariou v. Prince, 714 F.3d 694 (2d Cir. 2013). 
rentemente realizado con un teléfono inteligente o tablet) que mostraba no solo peces pequeños, sino también delfines que aparecían en los canales de Venecia como resultado del confinamiento comenzó a compartirse masivamente en internet y en las redes sociales. ${ }^{35} \mathrm{La}$ noticia fue recogida por varios medios de comunicación internacionales, incluidos MSN News (Christian, 2020), Gulf News (Gulzar, 2020) y Go News India (Alvi, 2020), algunos de los cuales habían incluído las imágenes. Sin embargo, la parte del video que mostraba los delfines no se había tomado en Venecia (Holroyd, 2020), sino en la isla italiana de Cerdeña, a cientos de miles de millas, y luego se había reunido con imágenes que mostraban los peces pequeños en un canal de Venecia (Daly, 2020).

¿Sería un video manipulado susceptible de ser protegido por derechos de autor o por derecho afín? En general, los videos caen dentro del objeto de los derechos de autor o de contenido protegido en la mayoría de las jurisdicciones. El CDPA del Reino Unido, por ejemplo, protege las películas, incluidas no solo las producidas por grandes cineastas, sino también grabaciones "en cualquier medio a partir del cual se pueda producir una imagen en movimiento por cualquier medio". ${ }^{36}$ Por lo tanto, una grabación como el video de delfines en principio está protegida por derechos de autor en el Reino Unido (así como en otras jurisdicciones de derecho consuetudinario, incluido EE. UU.), ${ }^{37}$ mientras que en otros países - por ejemplo, de la UE- este tipo de videos están protegidos mediante un derecho afín $^{38}$ (la diferencia entre "derechos de autor" y "derechos conexos"

35 Véase el video en https://www.youtube.com/watch?v=7Msyjxn-7GM.

36 Sec. 5B(1) CDPA.

37 Título 17 USC, Capítulo 1, que define "películas cinematográficas" como “... obras que consisten en una serie de imágenes relacionadas que, cuando se muestran en sucesión, transmiten una impresión de movimiento...”. Además, la Oficina de derechos de autor de EE. UU. señala que "[m]otión de imágenes son obras que contienen una serie o imágenes relacionadas que están destinadas a mostrarse con un proyector, pantalla digital u otro dispositivo. Cuando las imágenes se muestran en orden sucesivo, crean una impresión de movimiento que es perceptible a la vista" (véase el sitio web de la Oficina de derechos de autor de EE. UU.: https:/www.copyright.gov/ registration/motion-pictures).

38 Artículo 3, apartado 1, letra c), y artículo 9, apartado 1, letra c) de la Di- 
es predominantemente terminológica, ya que ambos les ofrecen a sus propietarios derechos exclusivos similares). También debe recordarse que, en la mayoría de los países, incluidos los de la UE, el Reino Unido y los EE. UU., los videos no necesitan ser originales para ser protegidos por derechos de autor o por un derecho afín, ya que estos no se consideran derechos de autor típicos. ${ }^{39}$ Por lo tanto, los videos de aficionados tomados con teléfonos inteligentes y tabletas, como se destaca aquí en el video de delfines, también están protegidos.

Aquí también pueden surgir problemas de infracción de derechos de autor. Esto sucedería si el video incorporara elementos con derechos de autor de filmaciones anteriores producidas por terceros, como pareciera haber sucedido con el video de delfines analizado en este apartado. De hecho, se descubrió que las imágenes de los delfines incorporadas en el video habían sido tomadas de otro video realizado por miembros del equipo de vela Luna Rossa durante su entrenamiento para la Copa América de 2021 en Cerdeña (Holroyd, 2020). Como observación general, debe tenerse en cuenta que el análisis sobre si un video infringe los derechos que posee el creador de un video anterior dependerá (nuevamente) de varios factores, incluido cuánto se ha tomado del video anterior (prueba de sustancia-

rectiva 2006/115 / CE del Parlamento Europeo y del Consejo, de 12 de diciembre de 2006, sobre el derecho de alquiler y el derecho de préstamo y sobre determinados derechos relacionados con los derechos de autor en este ámbito de propiedad intelectual (versión codificada).

39 En el Reino Unido, este tema se discutió en Hyde Park Residence Ltd. v. Yelland [2000] EWCA Civ., Un caso sobre la propiedad de los derechos de autor en cintas de video tomadas por la princesa Diana antes de su muerte: el tribunal señaló que "la propiedad y la subsistencia de los derechos de autor no estaban en disputa", porque "como aclara el artículo 1 de la Ley de 1988, el derecho de autor es un derecho de propiedad ", que era propiedad de la empresa de seguridad. El tema también se debatió en Estados Unidos. En el caso de 2008 Southwest Casino and Hotel Corp. v. Flyingman, Case Number CIV-07-949-C, US District Court, W.D. Oklahoma, un casino inició una demanda por infracción de derechos de autor por el uso de su video de vigilancia. El acusado señaló que el video no era lo suficientemente creativo como para ser protegido por los derechos de autor. La cuestión nunca se decidió porque la disputa terminó cuando un tribunal tribal sostuvo que el video era propiedad de tribus y no de la compañía del casino. 
lidad), la forma en que los jueces interpretan dicha prueba y otras reglas, como las de minimis.

Estos tres ejemplos de noticias falsas demuestran que las formas expresivas multiformes que adoptan tales noticias (artículos de revistas, fotografías y videos) en principio caen dentro del objeto de protección del derecho de autor y que dichas formas pueden satisfacer los requisitos de protección, a saber: originalidad y fijación (cuando se requiera). Si bien las imágenes modificadas pueden a veces no alcanzar el umbral de originalidad, particularmente cuando la obra anterior que se apropia no se modifica suficientemente, los artículos de revistas que incorporan noticias falsas a menudo se crean integralmente y, por lo tanto, pueden ser muy originales. En lo que respecta a los videos, debido a que no es necesario satisfacer un requisito de originalidad, ${ }^{40}$ la obtención de la protección de derechos de autor es más sencilla. Como se mencionó, con respecto a todos estos tipos de noticias falsas pueden surgir problemas de infracción en algunas circunstancias.

\section{5. ¿Se puede eximir la verificación de datos de la responsabilidad por infracción de derechos de autor?}

Vale la pena profundizar la cuestión de si el uso de noticias falsas por parte de los verificadores de hechos puede considerarse exento de responsabilidad por violación de derechos de autor, suponiendo que los derechos de autor subsistan en este tipo de obras y que los titulares de los derechos decidan hacerlos valer. La verificación de hechos se lleva a cabo no solo por organizaciones ad hoc, sino también por la prensa, los grupos de vigilancia de la gobernanza, las redes sociales, académicos y activistas. ${ }^{41}$

¿Cómo funciona la verificación de datos? Básicamente hay dos

40 Sin embargo, esto no significa que ningún video estará protegido. De hecho, no se ofrecerá protección a videos y películas que se copien de una película o video anterior. Véase, por ejemplo, la Sec. 5 (b) (4) CDPA, que establece que "los derechos de autor no subsisten en una película que es, o en la medida en que lo es, una copia tomada de una película anterior".

41 Para un análisis detallado sobre cómo funciona la verificación de datos, véase e.g. Al-Ash y Wibowo (2018), Chen et al. (2015), Conroy et al. (2015), Sharma et al. (2019), Shu et al. (2017). 
formas de detectar noticias falsas (Figueira y Oliveira, 2017, p. 820). La primera es confiar en la capacidad humana para distinguir entre hechos verdaderos y hechos falsos. Los periodistas y otros comunicadores suelen seguir este método. El segundo enfoque se basa en el uso de programas electrónicos automatizados y algorítmicos que verifican las fuentes de noticias (Figueira y Oliveira, 2017). Por lo general, la verificación automatizada de datos se basa en un sistema de monitoreo que examina periódicamente las principales revistas y periódicos, así como las noticias transmitidas, "utilizando fuentes de subtítulos y conversión de texto a voz” (Graves, 2018, s.p.), buscando elementos comunes, palabras clave, signos y símbolos que normalmente se encuentran en noticias falsas para poder detectar palabras o frases semánticamente similares (Karadzhov, 2017; Kertysova, 2019; Thorne y Vlacos, 2018). Este enfoque a menudo se basa en una combinación de características estilométricas y de vector de palabras basadas en el texto, ambas utilizadas para categorizar el contenido de una noticia, ${ }^{42}$ lo que hace posible analizar los elementos del texto y verificar "la autenticidad o autoría del mismo basado en el estilo lingüístico de la escritura" (Reddy et al., 2020, p. 212) (como el uso léxico, las estructuras sintácticas y el análisis de la fraseología).

Sin embargo, la verificación de datos automatizada y basada en el aprendizaje automático plantea dificultades, especialmente en las redes sociales. De hecho, algunos contenidos pueden ser tan hiperrealistas que es posible que los algoritmos no puedan percibir con un grado de suficiente certeza lo que ha sido manipulado y lo que no (Cao et al., 2017, p. 141; Shu et al., 2017, p. 22). Después de todo, cualquier proceso de verificación de hechos requiere con frecuencia una intervención humana manual preliminar o posterior para obtener estadísticas e investigación primaria a los fines de evaluar si las

42 Por ejemplo, la detección de noticias falsas en las redes sociales a menudo presenta una lista de atributos de contenido de noticias representativos, que incluyen: fuente (autor o editor del artículo de noticias); título (texto de título corto que tiene como objetivo captar la atención de los lectores que describen el tema del artículo); body text (texto principal de la noticia); imagen/video (parte del contenido del cuerpo de un artículo de noticias que proporciona elementos visuales de la historia). Ver Shu et al. (2017, p. 26). 
fuentes son confiables y si las afirmaciones son veraces (Vlachos y Riedel, 2014, p. 18). A pesar del rápido desarrollo de herramientas de verificación sofisticadas y automatizadas, es aún difícil imitar las evaluaciones contextuales sensibles requeridas en las actividades de verificación de hechos realizadas por humanos (Graves, 2018). Algunas herramientas automáticas de verificación de hechos pueden detectar una serie de afirmaciones fácticas simples cuando se dispone de datos claros, pero solo bajo la guía humana. Por ejemplo, la detección de noticias falsas en las plataformas de redes sociales a menudo se basa en un modelo híbrido doble que incluye la clasificación humana y el aprendizaje automático, que es capaz de filtrar cualquier tipo de contenido (foto, video o texto), así como la dinámica de propagación de noticias (como medios vinculados, reacciones de los usuarios y relaciones entre usuarios) (Figueira y Oliveira, 2017, p. 820). Por lo tanto, las plataformas de redes sociales generalmente usan y se basan en una combinación de sistemas automáticos para verificar el contenido más repetitivo y en la revisión humana para los casos multifacéticos (Kertysova, 2019).

En este contexto, Facebook ha adoptado un modelo interesante que se basa en una combinación entre los comentarios de los usuarios que señalan contenido potencialmente falso y el uso de múltiples modelos de aprendizaje automático para verificar continuamente el contenido de la plataforma (Figueira y Oliveira, 2017, p. 820). ${ }^{43}$ Cuando se identifica contenido falso, alterado, parcialmente falso o faltante, Facebook toma medidas. Si una imagen o información que circula en la plataforma parece dudosa, especialmente si no cita una fuente, una de las primeras actividades que realiza es estudiar los comentarios; de tal proceso puede eventualmente detectar información inconsistente o dar lugar a dudas sobre la autenticidad de un contenido (Gillespie, 2020). Otro modelo es utilizado por Full Fact, una organización benéfica británica que verifica y corrige los hechos contenidos en las noticias. Lo que hace esta organización es recopilar información de sitios de noticias, televisión en vivo o plataformas de redes sociales que pueden incluir afirmaciones que

43 Ver también Cómo funciona el programa de verificación... (2021). 
deben verificarse. ${ }^{44}$ Una vez que se recopila toda la información de entrada disponible como texto, se divide en oraciones individuales que constituyen su unidad atómica para las verificaciones de hechos. Luego, estas oraciones se pasan a través de una serie de pasos para que sean útiles en el proceso de verificación de datos.

Si bien el proceso para verificar la veracidad de noticias de solo texto puede ser relativamente estándar, verificar si las imágenes y los videos son veraces es más engorroso: aquí surge la necesidad de verificar si la imagen coincide con otros elementos, tales como la fecha en la que fue capturada y distribuida, varios detalles comprendidos en la imagen, condiciones climáticas, etc. Los verificadores de datos también intentan adquirir los archivos originales que incorporan la imagen para verificar si han sido alterados.

Dicho esto, en ese apartado se evalúa si ciertas excepciones a los derechos de autor pueden aplicarse a la verificación de hechos, a saber: (i) la doctrina general de uso legítimo según la ley de EE. UU. y varias defensas disponibles en la UE (y el Reino Unido); (ii) uso transitorio; (ii) minería de texto y datos; (iii) crítica y revisión; y (iv) seguridad pública. Poder contar con estas excepciones sería importante, ya que podría permitirles a los verificadores de hechos, incluidos aquellos que utilizan procesos automatizados ejecutados por plataformas, hacer su trabajo sin infringir los derechos de autor sobre las noticias cuya veracidad se evalúa, así como otras noticias que pueden usarse para fines de comparación.

Como es sabido, la doctrina de uso legítimo de los Estados Unidos permite el uso limitado de material protegido por derechos de autor sin necesidad de obtener la autorización del propietario del derecho. Un análisis preciso de uso legítimo debe basarse en la distinción entre uso expresivo y no expresivo del material protegido por derechos de autor. Si bien es posible que el primero no esté exento de la infracción de los derechos de autor, a menudo se considera que el segundo es suficiente para eludir la responsabilidad (Lim, 2019; Sobel, 2017). La jurisprudencia estadounidense existente en relación con ciertas empresas de tecnología ayuda a comprender dicha distinción, y tales principios podrían aplicarse mutatis mutandis a escena-

44 Véase la página web https://fullfact.org/automated. 
rios de verificación de hechos de noticias falsas. Dos casos relevantes son Kelly contra Arriba ${ }^{45}$ y Perfect10 contra Amazon. ${ }^{46}$ En ambos, los acusados proporcionaban servicios de motores de búsqueda de imágenes. Los demandantes Kelly y Perfect10 poseían derechos de autor que cubrían ciertas imágenes que habían sido reproducidas en forma de miniaturas, almacenadas en los servidores de los demandados y mostradas a los usuarios de internet que usaban los servicios de Arriba y Amazon. Los tribunales sostuvieron que las actividades del acusado eran usos legítimos transformadores y consideraron a los motores de búsqueda de imágenes administrados por los acusados como simples herramientas. Los tribunales estimaron que no se trataba de instrumentos utilizados para transmitir expresión y que el uso del material protegido por derechos de autor por parte de Arriba y Amazon había sido meramente instrumental, sin ningún propósito artístico o estético. ${ }^{47}$

Los tribunales de EE. UU. llegaron a conclusiones similares en otros dos casos: Authors Guild v. Google ${ }^{48}$ y AV ex rel. Vanderhye contra iParadigms. ${ }^{49}$ La primera disputa se centró en el Proyecto de bibliotecas de Google Books, que consiste en escanear y hacer disponible las colecciones de libros de las principales bibliotecas de investigación. El tribunal determinó que hacer copias de obras protegidas con el objetivo de facilitar y permitir la búsqueda e identificación de libros que contienen una palabra de interés de los buscadores es un uso transformador y, por lo tanto, justo. Dicho servicio, agregó el tribunal, no desplaza ni sustituye a los libros porque no es un instrumento que la gente use para leer los libros, sino que simplemente facilita su búsqueda. El segundo caso se centró en el servicio de detección de plagio Turnitin (el programa consiste en comparar los documentos

45 Kelly v. Arriba and Perfect10 v. Amazon (Kelly v. Arriba Soft Corp, 336 F.3d 811 (9th Cir. 2003).

46 Perfect 10, Inc. v. Amazon.com, Inc., 508 F.3d 1146 (9th Cir. 2007).

47 Para el primer reconocimiento judicial de uso justo no expresivo en los EE. UU., véase Sega Enterprises Ltd. v. Accolade, Inc., 977 F.2d 1510 (9th Cir. 1992).

48 Authors Guild, Inc. v. Google, Inc., 954 F. Supp. 2d 282 (S.D.N.Y. 2013); Authors Guild v. Google Inc., 804 F (3d) 202 (2nd Cir 2015).

49 A.V. ex rel. Vanderhye v. iParadigms, L.L.C., 562 F.3d 630 (4th Cir. 2009). 
presentados con su base de datos compuesta por grandes cantidades de papeles y material). Tampoco en este caso el juez encontró ninguna infracción de derechos de autor, habiendo considerado que el uso de copias digitales de obras con derechos de autor por parte del programa era totalmente ajeno al contenido expresivo, transformador y, por lo tanto, incapaz de producir un sustituto del mercado. Más precisamente, el tribunal estimó que Turnitin no usaba los documentos por su significado creativo y, aunque almacenara el documento completo, no había publicado una copia completa para que otras personas pudieran acceder a él y verlo.

En este contexto se podría argumentar que las actividades llevadas a cabo por los verificadores de hechos, es decir, la recopilación y el seguimiento de noticias falsas destinadas a controlar su veracidad (lo que podría implicar su reproducción), pueden en principio interferir con los derechos de autor de los creadores de esas noticias. Sin embargo, dichos usos podrían considerarse usos no expresivos ni creativos, pero transformadores de obras con derechos de autor $y$, por lo tanto, un uso justo según la ley de los EE. UU. De hecho, quien realiza la verificación de datos no usa noticias falsas con fines creativos, sino que dicho uso es más bien mecánico y se centra en un propósito específico, es decir, controlar si las noticias que se están verificando son veraces o falsas.

En cuanto a Europa, una excepción que potencialmente podría eximir ciertos usos mecánicos y no expresivos de las obras con derechos de autor por parte de los verificadores de hechos es la excepción de copia transitoria bajo la Directiva de la sociedad de la información. ${ }^{50}$ Esta disposición exime los actos de reproducción temporales siempre que sean transitorios o incidentales, parte esencial de un proceso tecnológico, permitan el uso lícito de una obra y no tengan un significado independiente. Se permite, entonces, la reproducción de una obra protegida por derechos de autor si la copia es necesaria para realizar tareas tecnológicas y mecánicas sin valor autónomo, siendo el ejemplo clásico la copia temporal de una página web almacenada en la caché del navegador. Por lo tanto, se puede observar que esta excepción podría cubrir escenarios en los que las entida-

50 Véase el artículo 5, apartado 1 de la Directiva 2001/29/CE sobre la armoni- 
des de verificación de hechos recopilan y monitorean noticias falsas, siempre que las copias de dicho material sean transitorias y no permanentes. Sin embargo, es dudoso que los verificadores de hechos hagan solo copias transitorias de noticias falsas, ya que la necesidad de monitorearlas y evaluarlas puede requerir un período de tiempo relativamente largo.

La excepción de extracción de texto y minería de datos en virtud de la Directiva de la UE de 2019 sobre derechos de autor en el mercado único digital también podría ser relevante en este caso. ${ }^{51}$ La actividad de extracción de texto y de minería de datos permite la captación y el uso de cantidades significativas de información disponible digitalmente; ${ }^{52}$ se considera una defensa útil en varios ámbitos, por ejemplo, para que resulte más fácil encontrar oportunidades comerciales y de investigación científica en documentos corporativos, feeds de redes sociales, registros médicos, artículos académicos y muchas otras fuentes de datos basados en texto. Según la literatura reciente (Reddy et al., 2020; Shu et al., 2017), la minería de texto y de datos también puede ser útil a la hora de detectar noticias falsas. Dicho esto, ¿podrían los verificadores de hechos que llevan a cabo tales actividades mineras invocar esta excepción? En teoría sí, pero debe tenerse en cuenta que la excepción de minería de datos según la Directiva de la UE es limitada. En primer lugar, esta actividad solo puede ser realizada libremente por organizaciones de investigación e instituciones de patrimonio cultural con fines de investigación científica. ${ }^{53}$ Por lo tanto, solo los verificadores de hechos que pertenecen a estas categorías - por ejemplo, aca-

zación de determinados aspectos de los derechos de autor y derechos afines en la sociedad de la información.

51 Véanse los artículos 3 y 4 de la Directiva (UE) 2019/790 sobre derechos de autor y derechos afines en el mercado único digital. El artículo 3, en particular, exime de la infracción de derechos de autor a la reproducción de material protegido por derechos de autor.

52 Véase el artículo 2 (2) de la Directiva (UE) 2019/790, que define la minería de datos y texto como "toda técnica analítica automatizada destinada a analizar textos y datos en formato digital a fin de generar información que incluye, sin carácter exhaustivo, pautas, tendencias o correlaciones".

53 Véase el artículo 3 de la Directiva 2019/790. La CDPA del Reino Unido también proporciona una excepción de extracción de texto y datos, que se limita a la copia de trabajos con el único propósito de investigación para un 
démicos involucrados en proyectos de investigación- podrían oponer esta defensa. Otra disposición de la Directiva permite, en principio, las actividades de extracción de texto y datos por parte de empresas y entidades con ánimo de lucro. ${ }^{54}$ Sin embargo, dicha excepción no se aplica si los titulares de los derechos de autor se han reservado el derecho, lo que significa que la excepción podría ser excluida con la mera declaración por parte de los titulares de los derechos de autor de no permitir tal actividad (Rosati, 2019). Por lo tanto, es posible que los verificadores de datos que detectan noticias falsas con fines de lucro (y varios lo hacen) no puedan utilizar esta excepción.

Existe otra defensa bajo la ley de la UE que los verificadores de hechos podrían tener en cuenta, es decir, la excepción de la crítica y revisión bajo la Directiva de la sociedad de la información. Esta defensa permite usos de una obra protegida por derechos de autor con la finalidad de criticarla y revisarla, siempre que dicha obra ya haya sido legalmente puesta a disposición del público, que se cite la fuente -incluido el nombre del autor-, que dichos usos se ajusten a las prácticas leales y en la medida requerida por el propósito específico. ${ }^{55}$ El CDPA del Reino Unido también contiene una excepción similar. ${ }^{56}$ La verificación de hechos de noticias falsas a menudo satisface los requisitos establecidos en estas disposiciones. Primero, la historia falsa que se verifica obviamente se ha puesto a disposición del público. De hecho, la razón misma por la que se utiliza la noticia es para verificar que sea veraz y, si no lo es, para informar al público (que ya ha estado expuesto a tales noticias) sobre la actividad de control y quién creó el contenido y lo difundió. En este sentido, se podría señalar que la copia de las fake news está dirigida a respaldar o ilustrar la crítica y revisión. El uso de noticias falsas con fines de verificación de hechos también parece un uso legítimo. La Directiva de la sociedad de la información y la CDPA del Reino Unido no proporcionan una definición legal de lo que es justo o injusto bajo

propósito no comercial: véase la Sección 29A de la CDPA.

54 Véase el artículo 4 de la Directiva 2019/790.

55 Artículo 5, apartado 3, letra d), de la Directiva 2001/29 / CE sobre la armonización de determinados aspectos de los derechos de autor y derechos afines en la sociedad de la información.

56 Section 30(1). 
esta excepción. Los tribunales tienen aquí discreción basada en los hechos específicos del caso y el objetivo para el cual se utiliza la obra protegida por derechos de autor. Dicho esto, se puede argumentar que la verificación de hechos de noticias que no se haga con fines meramente comerciales es justa, ya que su único propósito es verificar si la noticia es veraz, brindando así algunos beneficios sociales, culturales o informativos, sin interés económico directo o indirecto. Además, el hecho de que los verificadores puedan reproducir y mostrar las noticias falsas en su totalidad no hace que el uso de la obra protegida por derechos de autor sea injusto, ya que dicho uso es realmente necesario para tal fin. En general, se acepta que, en determinadas circunstancias, es justo reproducir y/o poner a disposición todo el trabajo protegido por derechos de autor a los fines de revisión o de crítica (este suele ser el caso de trabajos visuales, como fotografías o videos) (Bently et al., 2018, p. 247).

La excepción de seguridad pública bajo la Directiva de la sociedad de la información también podría asumir relevancia. ${ }^{57} \mathrm{Tal}$ disposición exime el uso de obras protegidas por derechos de autor "con fines de seguridad pública o para garantizar el correcto desempeño o la presentación de informes de procedimientos administrativos, parlamentarios o judiciales". Por lo tanto, se puede notar que los verificadores de hechos usan y reproducen la información en cuestión para perseguir un interés público, es decir, para averiguar si tales hechos son verdaderos o falsos y que, por lo tanto, están exentos de responsabilidad por derechos de autor en virtud de esta excepción. El hecho de que las actividades que tienen como objetivo verificar si una noticia es falsa protejan un interés público está confirmado por una vieja disputa extrajudicial inglesa de 1733, destacada por Will Slauter (2019) en su libro Who Owns the News? A History of Copyright. Este autor nos recuerda que en ese momento un periódico satírico de Londres llamado Grub-Street Journal, que se burlaba de políticos y redactores de noticias, fue acusado de copiar contenidos de terceros. De hecho, esta revista incorporaba regularmente noticias tomadas de otros periódicos de Londres y el editor buscaba diferentes informes sobre el mismo hecho y luego reproducía breves

57 Véase el artículo 5 (3) (e). 
extractos uno al lado del otro, reconociendo la fuente. Al poner lado a lado diferentes versiones de las mismas historias, el Grub-Street Journal sacó a la luz las inexactitudes y discrepancias que caracterizaban a la prensa de la época. Al ser acusado de prácticas injustas, el editor de la revista justificó tal comportamiento por motivos de utilidad pública, aclarando que "[nuestro] método de comparar los artículos con los de otro no solo no es pirata, sino extremadamente útil e incluso necesario para acabar con el negocio de las noticias falsas" (Slauter, 2019)..$^{58}$

Dicho esto, la jurisprudencia actual de la UE sobre la excepción de seguridad pública puede hacer difícil la aplicación de dicha defensa a los verificadores de hechos. En tal sentido, en Eva-Maria Painer ${ }^{59}$ la excepción fue interpretada de manera restrictiva por el Tribunal de Justicia de la Unión Europea (TJUE). En particular, el Tribunal sostuvo que no se puede permitir que las organizaciones privadas (en ese caso, un editor de periódicos) se arroguen la protección de la seguridad pública. Solo las autoridades públicas competentes pueden considerarse adecuadas y responsables de perseguir ese objetivo de interés general, lo que implica que ninguna otra entidad puede decidir de forma autónoma utilizar obras protegidas por derechos de autor invocando la excepción de seguridad pública ${ }^{60} \mathrm{El}$ TJUE reconoció que una entidad privada podría, en ciertos casos, contribuir al cumplimiento de un objetivo de seguridad pública. Sin embargo, dicha iniciativa -explicó el Tribunal-debe tomarse en el marco de una decisión o actuación de las autoridades nacionales competentes para garantizar la seguridad pública, así como a través de un convenio y en coordinación con dichas autoridades, aunque no es necesario basarse en un llamado a la acción específico, actual y expreso por parte de dichas autoridades. ${ }^{61}$ De ello se desprende que, a menos que los verificadores de datos operen en cooperación con las autoridades pertinentes (por ejemplo, el poder judicial), como se mencionó, no es posible aplicar esta excepción.

58 Ibídem.

59 Case C-145/10 Eva-Maria Painer v. Standard Verlags GmbH and Others, para 88.

60 Párrafos 111 a 112 de la decisión.

61 Párrafo 113 de la decisión. 


\section{6. ¿Excluir la elegibilidad de derechos de autor en noticias falsas por motivos de interés público?}

Hemos visto que las noticias falsas son, en principio, susceptibles de protección de los derechos de autor y pueden satisfacer los requisitos pertinentes, pero también que ciertos usuarios de noticias falsas, a saber, los verificadores de hechos, pueden eludir la responsabilidad por infracción de derechos de autor basándose en excepciones específicas.

En este apartado se abordará la cuestión de si se pueden negar los derechos de autor a noticias falsas en función de su naturaleza ilegal. El debate sobre si las obras cuyo contenido es ilegal o éticamente inaceptable deben ser protegidas por los derechos de autor no es nuevo. Algunos comentaristas creen que los regímenes de derechos de autor no deberían preocuparse por la naturaleza ilegal/inmoral de las obras, por lo tanto, permanecer "neutrales" (Bonadio y Lucchi, 2018a, p. 418). La principal justificación de este enfoque basado en la neutralidad subyace en la creencia de que actuar como censor excede el mandato de la ley de derechos de autor, además de que no proteger las obras en función de su contenido podría producir un efecto paralizador en la creatividad, sobretodo porque impondría una carga excesiva para quienes deciden qué obras deben obtener protección (Haber, 2018, p. 409).

De hecho, los jueces de varios países han confirmado a menudo que las obras que muestran contenidos ilegales o inmorales merecen protección de los derechos de autor. Por ejemplo, en Italia, un himno fascista, ${ }^{62}$ el libro de Adolf Hitler Mein Kampj ${ }^{63}$ y una parodia obscena ${ }^{64}$ se han considerado sujetos a derechos de autor. Las obras relacionadas con la pornografía, especialmente las películas, también son relevantes ya que tribunales de muchos países, inclui-

62 Ponti DeLaurentis S.p.A. v. Pellegrino, Court of Appeal of Rome, 10 October 1957.

63 Court of Bologna (Pretura), 20 April 1971, Civil Justice 1971, 694.

64 Susanna Tamaro and Soc. Baldini e Castoldi v. Soc. Comix and Soc. P.D.E., Court of Milan, 29 January 1996. 
dos EE. UU., ${ }^{65}$ Francia, ${ }^{66}$ Taiwán ${ }^{67}$ e Italia, ${ }^{68}$ han confirmado que tales obras son protegidas por derechos de autor. En cuanto al Reino Unido, la CDPA no excluye explícitamente la protección de obras escandalosas o indecentes. En un caso anterior a la CDPA de 1916, es decir, Glyn v. Weston Feature Film Company, ${ }^{69}$ el tribunal se negó a otorgar una orden judicial por infracción de los derechos de autor de la obra dramática del demandante porque el episodio descrito en su

65 Hay dos asuntos importantes relacionados con la pornografía en EE. UU. que respaldan esta opinión. El primero es Mitchell Bros. Film Group v. Cinema Adult Theatre (604 F.2d 852 (5th Cir. 1979), certificado denegado, 445 U.S. 917 (1980)); y el otro es Jartech v. Clancy, 666 F.2d 403 (9th Cir. 1982). Ambos asuntos rechazaron la idea de que la obscenidad puede ser una defensa contra la infracción de los derechos de autor. El Quinto Circuito en Mitchell Bros. en particular estimó que "aquí ni siquiera hay un indicio en el lenguaje [de la Ley de Derechos de Autor] de que la naturaleza obscena de una obra la convierte en un 'escrito' menos protegido por derechos de autor. No existe otro lenguaje legal del que se pueda inferir que el Congreso tenía la intención de que los materiales obscenos no tuvieran derechos de autor. [...] La historia de las restricciones de los derechos de autor basadas en el contenido [...] sugiere que la ausencia de tales limitaciones en la Ley de Derechos de Autor [...] es el resultado de una elección política intencional y no simplemente una omisión". Sin embargo, en un caso posterior, Devils Films Inc. V. Nectar Video, 29 F. Supp. 2d 174 (S.D.N.Y.1998), el tribunal se negó a seguir a Mitchell Bros. y no otorgó una orden judicial o una orden de embargo en relación con películas consideradas obscenas. Lo hizo apoyándose en la doctrina de las "manos inmundas" (sobre la cual ver también más abajo nota 147). Este hallazgo probablemente se deba al hecho de que el acusado había distribuido ilegalmente las películas obscenas a través del comercio interestatal, haciendo que todo el comportamiento no solo fuera inmoral, sino también ilegal (lo que lo distingue de Mitchell). El principio de Mitchell Bros se restableció posteriormente en Nova Prods., Inc. v. Kisma Video, Inc., Nos. 02 Civ. 3850 (HB), 02 de lo civil. 6277 (HB), 03 de lo civil. 3379 (HB), 2004 WL 2754685, en * 3 (S.D.N.Y. 1 de diciembre de 2004).

66 Dauphin Pirate case (TGI de Lyon, ch. 10 cab. 10 J, decision of 7 February 2017).

67 Sentencia penal 101 Xing-Zhi-Shang-Yi-Zi No. 74 (2012) del Tribunal de Propiedad Intelectual de Taiwán. Para un análisis del caso, véase Ping-Hsun (2014).

68 Imp. Valerio Basaglia, Italian Supreme Court, 2 June 1995 n. 908.

69 Glyn v. Weston Feature Film [1916] 1 Ch. 261, 261. 
novela que había sido supuestamente pirateada por los acusados era, en opinión del Tribunal, tremendamente inmoral en su esencia, en su tratamiento y en su tendencia. Sin embargo, el tribunal también reconoció incidentalmente que las obras potencialmente obscenas podrían estar amparadas bajo ciertas circunstancias. Por otra parte, podría decirse que desde entonces las normas sociales han cambiado sustancialmente y la inmoralidad a través de actos sexuales no se considera del todo buena o mala, particularmente en un medio más basado en el entretenimiento, como la pornografía.

Que los derechos de autor deban ser neutrales con respecto al contenido de la obra también fue confirmado por la decisión de un Panel de la Organización Mundial del Comercio (OMC) en la disputa entre Estados Unidos y China sobre la aplicación de los derechos de la propiedad intelectual (PI),$^{70}$ que concluyó que la denegación de la protección de derechos de autor por parte de China en relación con obras que no cumplen con lo establecido en las normas de "revisión del contenido" de dicho país no se ajustan al Acuerdo sobre los ADPIC. El Panel, en particular, sostuvo que los derechos de autor y la censura del Gobierno abordan diferentes derechos e intereses, y que mientras que los derechos de autor protegen los derechos privados, la censura del Gobierno se ocupa del interés público. Por lo tanto, las disposiciones sobre la censura -señaló además el Panel- no pueden eliminar los derechos que son inherentes a una obra protegida por derechos de autor.

Entonces ¿qué ocurre con las noticias falsas? Si seguimos plenamente el enfoque de "neutralidad" de los derechos de autor, llegaríamos a la conclusión de que dichas noticias deberían considerarse protegidas por derechos de autor a pesar de que tienen el objetivo (y son capaces) de engañar a muchas personas. ¿Es así? ¿Debería la ley de derechos de autor hacer la vista gorda ante los riesgos que plantea este fenómeno y permitir que los creadores de este tipo de contenido recurran a sus derechos sustantivos y de ejecución para maximizar las ganancias? Creemos que esto no debería ser de este modo, ya que los peligros que surgen de las noticias falsas son mayores que los derivados, por

70 WTO case DS362 China - Measures Affecting the Protection and Enforcement of Intellectual Property Rights, report of 26 January 2009. 
ejemplo, de un libro que se basa en hechos falsos (como en Nash v. CBS) o una película pornográfica (Snow, 2015). En tal sentido, como hemos visto, las fake news se producen a menudo con el propósito de alterar el discurso político y social, por ejemplo, desacreditando a una figura pública o a un movimiento político. Es suficiente considerar la información falsa sobre la fotografía modificada digitalmente de Angela Merkel: millones de usuarios de las redes sociales creyeron que Arabia Saudita TV había efectivamente censurado la imagen de la líder alemana con la cabeza descubierta, contribuyendo así a dar lugar o a fortalecer un sentimiento antiárabe y antimusulmán. Esto es más peligroso que publicar y distribuir libros que se basan en hechos falsos, ya que en este último caso los lectores de dichos libros optan por comprar el producto como tal, que, por lo tanto, no se les impone. Lo mismo ocurre con el contenido escandaloso o éticamente controvertido, como las obras pornográficas, que son solicitadas activamente por lectores y espectadores. Las noticias falsas modernas son diferentes. Los artículos falsos, así como las imágenes y los videos falsos, manipulados o engañosos pueden llegar fácil y rápidamente a millones de personas a través de las redes sociales, exponiéndolas de manera pasiva a hechos falsos y/o distorsionados con consecuencias y repercusiones que son potencialmente de amplio alcance y extremadamente dañinas. La alarma social de las noticias falsas tiene sus raíces en su naturaleza inherente: es decir, que se muestra y se presenta no ya como una ficción, sino como hechos verdaderos con el objetivo de engañar a las personas e impulsarlas a confiar en dicha información falsa. Los efectos negativos de esta distorsión de la verdad pueden verse amplificados por los medios tradicionales que recogen las noticias falsas. Esto sucedió con el video que afirmaba que habían aparecido delfines en las aguas de Venecia: el video manipulado fue recogido por varios medios de comunicación, magnificando así su impacto.

La académica estadounidense Cathay Smith (2019) sugirió que a las noticias falsas se les debe negar los derechos de autor por estos motivos. Asimismo, señala que "los hechos que engañan son dañinos para la sociedad porque distorsionan la historia, dan forma falsa a nuestra visión de la sociedad y proporcionan información errónea para la posteridad" (p. 237).

Por lo tanto, la protección de los derechos de autor debe recha- 
zarse -argumenta Smith (2019, p. 242)-, ya que en estos casos prevalece el interés público en promover la eficiencia, la equidad y la realización de obras socialmente valiosas. Más específicamente propone aplicar la doctrina de impedimento fáctico con el fin de excluir la protección de hechos falsos, y lo hace poniendo de relieve una serie de casos jurisprudenciales estadounidenses que se han basado explícita o implícitamente en esa doctrina ${ }^{71}$ (en las jurisdicciones de derecho común, el estoppel es una doctrina que se invoca en algunas circunstancias para evitar que una persona se base en ciertos derechos o algunos hechos que son diferentes de los hechos anteriores). Smith (2019) también plantea cuestiones económicas, señalando que "los autores de hechos falsos no deberían poder beneficiarse de su engańo" (p. 227). De hecho, como hemos visto, las noticias falsas se crean a menudo para atraer clics y así aumentar las ganancias, incluso cuando no hay intención de contaminar el discurso político (el video de los delfines de Venecia pertenece a esta categoría).

Una de las decisiones anteriormente citadas relacionada con las

71 Véase, entre otros, Oxford Book Co. v. Coll. Entrance Book Co., 98 F.2d 688, 691 (2d Cir. 1938) (sostiene que "los hechos históricos no son derechos de autor per se ni son errores de hecho"); Mosley contra Follett, núm. 80 de lo civil. 5628, 1980 WL 1171, en 1, 3 (SDNY, 5 de noviembre de 1980) (concluyendo que el acusado se había basado razonablemente en las declaraciones del autor de que la obra no era ficticia, y se centró en tal confianza y finalmente considerándola razonable debido a la categorización del trabajo del autor por la Biblioteca del Congreso como no ficción y al tratamiento del trabajo por parte de los revisores como no ficción); Marshall v. Yates, No. CV81-1850-MML, 1983 WL 1148, en 2 (C.D. Cal. 26 de octubre de 1983) (adoptando nuevamente el requisito de confianza razonable para el impedimento fáctico). Smith (2019) también cita casos que rechazaron explícitamente el requisito de que el acusado debe demostrar confianza, sosteniendo en cambio que dicha confianza no es concluyente cuando se trata de aplicar la doctrina de impedimento fáctico: ver Arica Inst., Inc. v. Palmer, 970 F.2d 1067, 1069 (2a Cir. 1992); Houts contra Universal City Studios, Inc., 603 F. Supp. 26, 31 (C.D. Cal. 1984); y casos que se han negado a aplicar o rechazado esta doctrina: De Acosta v. Brown, 146 F.2d 408, 409 (2d Cir. 1944); Penguin Books U.S.A., Inc. contra New Christian Church of Full Endeavour, Ltd., No. 96 CIV. 4126 (RWS), 2000 WL 1028634, en 3 (S.D.N.Y. 25 de julio de 2000); Gerald Brittle contra Warner Bros. Entrit, Inc., No. 3: 16-cv00908-JAG (E.D. Va., 28 de agosto de 2017). 
noticias que ha recurrido a la doctrina de estoppel fáctico, es decir, Davies v. Bowes (1913), ${ }^{72}$ también enfatizó el elemento económico dentro del análisis de la injusticia. En esa antigua disputa, un escritor del periódico neoyorquino The Sun había publicado una historia ficticia sobre la escena de un tribunal que pretendía ser un "drama de la vida real" en un pequeño pueblo de Massachusetts. Sin embargo, la historia se había presentado como si fuera un informe periodístico de un hecho real. Otro autor creyó que el relato era cierto y lo utilizó como base para una obra de teatro llamada Kindlining. El primer escritor lo demandó, argumentando que la obra constituía una violación de su derecho a dramatizar la obra. El juez Hough no concedió la orden judicial porque consideró que presentar una ficción como noticia y beneficiarse de la adaptación de su historia por parte del acusado era inmoral. En particular, en la sentencia señaló:

es una cuestión de moral que quien presente una cosa como verdad no será escuchado alegar con fines de lucro que es ficción. [...] Porque la historia se difundió como noticia; se presentó al público como un hecho y no como una ficción; los lectores de The Sun fueron invitados a creerla. (Slauter, 2019, p. 243)

La inmoralidad inherente a la explotación de las noticias falsas también podría ser útil a los fines de invocar la doctrina de las "manos inmundas". Se trata de una defensa equitativa típica de jurisdicciones de common law-como la estadounidense-, en la que el demandado alega que el demandante no debe obtener reparación y/o beneficio cuando este último ha actuado de forma poco ética, de mala fe o de todos modos ha llevado a cabo una actividad ilegal. ${ }^{73}$ Esta podría ser

72 Davies v. Bowes, 209 F.53, 55 (SDNY 1913) (señalando también que el periodista que había realizado la noticia falsa publicó su artículo como tal y los acusados se basaron en dicho artículo en su carácter de noticia; y concluyó que el periodista fue excluido de hecho argumentando que sus noticias merecían el tipo de copyright que la ficción generalmente atrae).

73 La doctrina tiene sus raíces en la historia. En el antiguo asunto Reino Unido Holman v. Johnson (1775) 1 Cowp 341, un caso de derecho contractual inglés que se centra en los principios subyacentes a las transacciones ilegales, lord Mansfield señaló: "Ningún tribunal prestará su ayuda a un hombre que 
otra vía legal para evitar que los creadores de noticias falsas se beneficien efectivamente de los derechos de autor $y$, en primer lugar, gocen de un incentivo para elaborarlas y/o distribuirlas. Del mismo modo, la CDPA del Reino Unido podría servir en caso de que una disputa sobre la protección de los derechos de autor de las noticias falsas llegara a un tribunal británico: la sección 171 (3) establece que ninguna disposición de derechos de autor en ese estatuto afectará "cualquier estado de derecho que impida o restrinja la aplicación de los derechos de autor, por motivos de interés público". ${ }^{74}$ Por lo tanto, esta disposición no establece que la materia controvertida no sea susceptible de derechos de autor por motivos de política pública (Laddie et al., 2018 , $\$ 21-20)$. En cambio, contiene un saving con respecto a cualquier estado de derecho que impida o restrinja el cumplimiento de los derechos de autor si esto es necesario para proteger un interés público. En el asunto Reino Unido Hyde Park Residence Ltd. v. Yelland se sostuvo que el objetivo de esta disposición es permitir que los tribunales no hagan cumplir ningún derecho de autor cuando la obra sea perjudicial para la vida pública. ${ }^{75}$ Entonces se puede cuestionar: ¿qué es más "perjudicial" que contaminar el discurso político mediante la difusión de noticias falsas y/o la extracción de beneficios de dicha actividad?

funda su causa en un acto inmoral o ilegal. Si de la propia declaración del demandante o de otra forma, la causa de la acción parece surgir ex turpi causa, o de la transgresión de una ley positiva de este país, en tal caso el tribunal sostiene que el demandante no tiene derecho a ser asistido". En esta dirección va el tribunal; no por el bien del demandado, sino porque no prestarán su ayuda a tal demandante. Además, en otro asunto más reciente, Euro-Diam Ltd. v. Bathurst [1988] 2 All ER 23, 27-28, un caso inglés relacionado con la indemnización derivada de un contrato de seguro, señaló que el principio ex turpi causa "se aplica si, en todas las circunstancias, sería una afrenta a la conciencia pública otorgar al demandante la reparación solicitada/demandada porque implicaría que el tribunal favorece o alienta al demandante en su conducta ilegal o bien alentaría otros a cometer actos similares".

74 Sec. 171(3) CDPA. La excepción a la infracción de derechos de autor por interés público se aceptó en Ashdown v. Telegraph Group Ltd. [2001] EWCA Civ 1142. Si bien tal defensa no ha sobrevivido a las decisiones del TJUE en Spiegel Online (C-516/17) y Funke Medien (C-469/17), después del Brexit podría volver a asumir relevancia.

75 Hyde Park Residence Ltd. v. Yelland [2000] 3 W.L.R. 215 [2001] Ch. 143. 
Los argumentos anteriores parecen sólidos. Después de todo, muchos estarían de acuerdo con que ninguna ley debería proteger los intereses de los creadores de obras que unánimemente se consideren perjudiciales para la sociedad. Los actos ilegales que son particularmente graves $y / u$ odiosos (no solo noticias falsas, sino también pornografía infantil, por ejemplo) no deben ser recompensados por los regímenes de derechos de autor. ${ }^{76}$ Como se ha señalado, estas obras son (socialmente) indeseables, por lo que otorgarles protección contribuiría a crear una injusticia social y podría percibirse como una especie de aprobación gubernamental de un acto ilegal y/o aborrecible en su esencia (Haber, 2018, p. 410). Un modo en el que estos actos ilegales o inaceptables podrían desalentarse es exactamente bloquear cualquier posible incentivo legal dado por la ley de derechos de autor, particularmente la perspectiva de maximizar las ganancias.

La principal objeción a este punto consiste en que negarse a otorgar derechos de autor a las noticias falsas o dejar sin efecto dichos derechos aumentaría potencialmente su difusión. En ausencia de derechos de autor, sostiene este argumento, la noticia podría ser reproducida libremente, incluso textualmente, y puesta a disposición del público por los medios de comunicación y/o por cualquier otra persona interesada en difundirla sin temor a incurrir en responsabilidad por infracción de derechos de autor, lo que en definitiva amplificaría en vez de neutralizar los efectos negativos producidos por este fenómeno.

Sin embargo, existen respuestas válidas a esta objeción. Como se mencionó anteriormente, debido a que los creadores de noticias falsas a menudo pueden verse incentivados por la perspectiva de lucro (que los derechos de autor les permiten maximizar), sustraendo la protección autoral a las noticias falsas, puede -simétricamente- contribuir a desalentar su elaboración y/o difusión. Si bien aún no hay constancia de casos en los que los creadores de noticias falsas hayan

76 No se trata de actividades ilegales menos graves como el arte callejero o el grafiti no autorizado. En otras publicaciones, uno de los autores del presente artículo argumentó que el hecho de que tales obras de arte se creen sin la autorización del propietario del soporte tangible (por ejemplo, un muro) no debería ser concluyente cuando se trata de la subsistencia de los derechos de autor (Bonadio, 2019). 
invocado explícitamente los derechos de autor para maximizar sus ganancias (por ejemplo, a través de licencias), no se puede descartar que una de las razones que conducen a estos creadores a elaborar tales noticias provenga de ser conscientes de que los derechos de autor subsisten y que podrían ser explotados si surgiera la necesidad. Por tanto, excluir la protección de derechos de autor puede favorecer la lucha contra la difusión de noticias falsas. También se podría argumentar que negar los derechos de autor no tendría el efecto de aumentar la circulación de noticias falsas; esto se debe a que pueden aplicarse otras restricciones (como las que surgen de las recientes leyes contra las noticias falsas) que también tienen como objetivo desalentar dicha difusión. Esto no implica asumir que no garantizar los derechos de autor sería inútil, sino más bien todo lo contrario. Un régimen que combine la ausencia de derechos de autor y la presencia de reglas que combatan las noticias falsas tendría más posibilidades de reducir la cantidad de información falsa que inunda regularmente la web y llega a las redes sociales.

\section{Observaciones finales}

Las fake news son un fenómeno preocupante y su impacto negativo en la sociedad es innegable. Los Gobiernos están comenzando a reaccionar, pero es posible que sean necesarias medidas adicionales para abordar y finalmente derrotar este fenómeno, incluso cuando tales medidas puedan interferir con el derecho a la libre expresión. Como se ha podido observar, es más probable que tales medidas/ iniciativas se materialicen en Europa que en los EE. UU.

Las formas expresivas que toman las noticias falsas, incluidos artículos de revistas, fotografías y videos, constituyen en principio un contenido sujeto a derechos de autor y, con frecuencia, pueden satisfacer los requisitos de protección, es decir, originalidad y fijación (cuando sea relevante). Los tres ejemplos analizados, es decir, el artículo que afirma que el papa Francisco apoyó a Donald Trump, la fotografía modificada digitalmente de Angela Merkel y el video manipulado que muestra delfines en Venecia son solo algunos ejemplos de los muchos tipos de noticias falsas que pueden ser susceptibles de derechos de autor y que cumplen con los requisitos de protección pertinentes. 
Si bien no existen constancias de casos en los que el creador de una noticia falsa se haya basado en los derechos de autor, por ejemplo, para oponerse a su explotación, no se puede descartar que ya haya habido objeciones basadas en derechos de autor (que no han llegado a los tribunales y, por lo tanto, han permanecido confidenciales), posiblemente con el objetivo de salvaguardar los beneficios económicos que tales noticias pueden generar. Por ello es que la ardua discusión esbozada en este artículo no es meramente académica y de allí que la decisión de no proteger las noticias falsas a través de los derechos de autor, que podrían tomar la legislatura o incluso los tribunales mientras desarrollan su jurisprudencia (especialmente en las jurisdicciones de derecho anglosajón), puede tener un efecto disuasorio. Si quien elabora noticias falsas es consciente de que no puede invocar el derecho de autor de ninguna manera, es posible que esté menos inclinado a realizarlas y/o difundirlas. Cabe recordar que los realizadores de contenido falso suelen estar motivados por incentivos económicos (Kshetri y Voas, 2017). El contenido que se vuelve viral en las plataformas de redes sociales puede generar ingresos significativos de publicidad cuando los usuarios hacen clic y acceden a dicho contenido. En un esfuerzo por mitigar eficazmente este fenómeno, la negación de los derechos de autor puede contribuir a romper el círculo de transmisión de este tipo de información y el modelo de negocio en el que se basa. En otras palabras, la ausencia de exclusividad de derechos de autor puede tener el efecto de desalentar la creación y difusión de noticias falsas, ya que erosionaría el incentivo financiero subyacente (Snow 2015). Como se ha señalado, "si la obra no goza de protección es más difícil cosechar recompensas por su distribución, lo que significa que es probable que se distribuya menos" (Siebrasse, 2001).

Rechazar la protección de los derechos de autor con respecto a noticias falsas también estaría en sintonía con la teoría utilitaria de la propiedad intelectual, que, como es sabido, es popular en los EE. UU. y está consagrada en su Constitución: la sección 1 (8) dice que la protección de la propiedad intelectual es necesaria para "Promover el progreso de la ciencia y las artes útiles". ${ }^{77}$ Este principio también ha

77 Énfasis agregado. 
caracterizado la ley de derechos de autor del Reino Unido durante siglos. El Estatuto de Ana de 1710 (la primera ley de derechos de autor en el mundo) se tituló "Una ley para el fomento del aprendizaje". ${ }^{78}$ Pero ¿"promover" y "alentar" las noticias falsas es a lo que deberían aspirar las leyes de derechos de autor? La respuesta es ciertamente "no". Las jurisdicciones que no adoptan explícitamente las teorías utilitarias de la propiedad intelectual, pero que siguen predominantemente un enfoque basado en los derechos naturales (como los países de Europa continental), también podrían justificar la decisión de excluir la protección de los derechos de autor en relación con noticias falsas. En estos casos, la exclusión podría fundarse en los motivos relacionados con la equidad. Después de todo, ¿cómo podría uno razonablemente afirmar que las leyes de derechos de autor deberían proteger el derecho "natural" a engañar a la gente y beneficiarse económicamente de tal engaño?

Las noticias falsas no benefician a la sociedad. La dañan y la perjudican, socavando el tejido social y político que une a las personas o a las organizaciones que estas forman. Negar explícitamente los derechos de autor en noticias falsas contribuiría a desalentar comportamientos que, a pesar de ser creativos y a veces muy originales, son dañinos y no contribuyen a la sociedad. Esto se lograría eliminando cualquier incentivo económico y/o reafirmando principios de equidad y de sentido común. En caso de que se reconozca la existencia de derechos de autor con respecto a noticias falsas, las excepciones, incluidas algunas de las defensas destacadas en este artículo, podrían (y deberían) estar disponibles para entidades e individuos que realicen tareas de verificación de hechos.

\section{Bibliografía}

Al-Ash, H. S. y Wibowo, W. C. (2018). Fake News Identification Characteristics Using Named Entity Recognition and Phrase Detection. 10th International Conference on Information Technology and Electrical Engineering (ICITEE). pp. 12-17

78 Énfasis agregado. 
Alemanno, A. (2018). How to Counter Fake News? A Taxonomy of Anti-fake News Approaches. European Journal of Risk Regulation, 9(01), 1-5.

Allcott, H. y Gentzkow, M. (2017). Social Media and Fake News in the 2016 Election. Journal of Economic Perspectives, 31(2), 211-236.

Alvi, R (2020). Dolphins Return To Venice Canal As Pollution Drops Amid Lockdown. Gonewsindia. https://www.gonewsindia.com/latest-videos/international/swans-dolphins-return-to-venice-canal-as-pollution-drops-amid-lockdown-10772.

Balganesh, S. (2011). "Hot News": The Enduring Myth of Property in NewsColumbia. Law Review, (111), 419-497.

Bartlett, E. (16 de julio de 2020). No, Saudi State Television Did Not Blur out Angela Merkel's Hair. Inews.co.uk. https://inews.co.uk/news/world/angela-merkel-hair-saudi-arabia-6306.

Bently, L. (2016). Response to Article 11 of the Proposal for a Directive on Copyright in the Digital Single Market: Modernising the European Copyright Framework. https://www.cipil.law.cam.ac.uk/sites/www.law.cam.ac.uk/files/ images/www.cipil.law.cam.ac.uk/documents/ipomodernisingipprofresponsepresspublishers.pdf.

Bently, L., Sherman, B., Gangjee, D. y Johnson, P. (2018). Intellectual property law. Oxford University Press.

Bonadio, E. (2019). The Cambridge Handbook of Copyright in Street Art and Graffiti (Cambridge Law Handbooks). Cambridge University Press.

Bonadio, E. y Lucchi, N. (2018a). Copyright and Pornography. En Bonadio, E. y Lucchi, N. (Eds.), Non-conventional copyright: do new and atypical works deserve protection? (pp. 418-431). Edward Elgar Publishing.

Bonadio, E. y Lucchi, N. (2018b). Non-conventional copyright: do new and atypical works deserve protection? Edward Elgar Publishing.

Boyle, J. (2008). The public domain : enclosing the commons of the mind. Yale University Press.

Braun, J. A. y Eklund, J. L. (2019). Fake News, Real Money: Ad Tech Platforms, Profit-Driven Hoaxes, and the Business of Journalism. Digital Journalism, $7(1), 1-21$.

Cao, J., Qi, P., Sheng, Q., Yang, T., Guo, J. y Li, J. (2020). Exploring the Role of Visual Content in Fake News Detection. En Shu, K., Wang, S., Lee, D. y Liu, H. (Eds.), Disinformation, misinformation, and fake news in social media: emerging research challenges and opportunities. Springer.

Castells, M. (2010). The Power of Identity (2a ed.). Wiley-Blackwell.

Chen, Y., Rubin, V. L. y Conroy, N. (2015). Towards News Verification: Deception Detection Methods for News Discourse. HICSS2015. https://ir.lib.uwo.ca/fimspres/46

Chiou, L. y Tucker, C. E. (2018). Fake News and Advertising on Social Media: A Study of the Anti-Vaccination Movement. SSRN Electronic Journal.

Christian, B. (2020). Dolphins and Swans Appear in Venice Canals a Week after City Locks Down to Prevent Coronavirus Spread. MSN News. https:// 
www.msn.com/en-nz/news/coronavirus/dolphins-and-swans-appear-in-venice-canals-a-week-after-city-locks-down-to-prevent-coronavirus-spread/ ar-BB11oWGo?li=BBqdg4K.

Cómo funciona el programa de verificación de datos independiente de Facebook. (1 de junio de 2021). Meta Journalism Project. https:/www.facebook.com/journalismproject/programs/third-party-fact-checking/how-it-works.

Conroy, N. J., Rubin, V. L. y Chen, Y. (2015). Automatic deception detection: Methods for finding fake news. Proceedings of the Association for Information Science and Technology, 52(1), 1-4.

Copyright Alliance (2017). Is Fake News Protected By Copyright. https://copyrightalliance.org/education/qa-headlines/is-fake-news-protected-by-copyright/.

Couch, C. J. (1990). Mass communications and state structures. The Social Science Journal, 27(2), 111-128.

Daly, N. (20 de marzo de 2020). Bogus stories of wild animals flourishing in quarantined cities gives false hope-and viral fame. National Geographic. https://www. nationalgeographic.co.uk/animals/2020/03/fake-animal-news-abounds-social-media-coronavirus-upends-life.

Digital Shadows (2017). The Business of Disinformation: A Taxonomy. http://info. digitalshadows.com/rs/457-XEY-671/images/DigitalShadows-TheBusinessofDisinformationFakeNews.pdf.

European Commission (2018). A multi-dimensional approach to disinformation. Report of the independent High Level Group on fake news and online disinformation. https://op.europa.eu/en/publication-detail/-/publication/6ef4df8b-4cea-11e8-be1d-01aa75ed71a1 .

European Commission \& High Representative of the Union for Foreign Affairs and Security Policy. (2018). Joint Communication to the European Parliament, the European Council, the Council, the European Economic and Social Committee and the Committee of the Regions Action Plan against Disinformation. Brussels, 5.12.2018 JOIN(2018). 36 final.

Figueira, L. y Oliveira, L. (2017). The current state of fake news: challenges and opportunities. Procedia Computer Science, 121, 817-825.

Flauss, J. F. (2009). The European Court of Human Rights and the freedom of expression. Indiana Law Journal, (84), 809-849.

Gillespie, T. (2020). Platforms Throw Content Moderation at Every Problem. En Zimdars, M. y McLeod, K. (Eds), Fake News: Mis/Disinformation in a Digital Age (pp. 329-339). MIT Press.

Graves, L. (2018). Understanding the Promise and Limits of Automated Fact-Checking. https://agency.reuters.com/content/dam/openweb/documents/pdf/ news-agency/report/reuters-institute-graves-factsheet-180228.pdf.

Gu, L., Kropotov, V., Yarochkin, F., Leopando, J. y Estialbo, J. (2017). Fake News and Cyber Propaganda: The Use and Abuse of Social Media. Trendmicro. https:// www.trendmicro.com/vinfo/us/security/news/cybercrime-and-digital-threats/ fake-news-cyber-propaganda-the-abuse-of-social-media. 
Gulzar, F. (19 de marzo de 2020). Italy: Dolphins return to Venice's canals as public under coronavirus lockdown. Gulf News. https://gulfnews.com/world/europe/ italy-dolphins-return-to-venices-canals-as-public-under-coronavirus-lockdown-1.1584624481080.

Haber, E. (2018). Copyright Protection of Illegal Works. En Bonadio, E. y Lucchi, N. (Eds.), Non-conventional copyright: do new and atypical workers deserve protection? (pp. 401-417). Edward Elgar Publishing.

Haenschen, K. y Ellenbogen, P. (14 de diciembre de 2016). Disrupting The Business Model of the Fake News Industry. Freedom to Tinker. https://freedom-to-tinker. com/2016/12/14/disrupting-the-business-model-of-the-fake-news-industry/.

Holroyd, M. (7 de septiembre de 2020). Debunked: Video does NOT show dolphins in Venice's canals. Euronews. https://www.euronews.com/2020/03/20/ debunked-video-does-not-show-dolphins-in-venice-s-canals-thecube

House of Commons. (2018). Disinformation and "fake news": Interim Report. Fifth Report of Session 2017-19. Report, together with formal minutes relating to the report. https://publications.parliament.uk/pa/cm201719/cmselect/cmcumeds/363/363.pdf.

Humphrey, J. (2017). The Plague of Fake News and the Intersection with Trademark Law. Cybaris An Intellectual Property Law Review, (8), 127-154.

Karadzhov, G. (1 de octubre de 2017). Fully Automated Fact Checking Using External Sources. ArXiv.Org. https://arxiv.org/abs/1710.00341.

Karapapa, S. (2018). The Press Publishers' Right in the European Union: An Overreaching Proposal and the Future of News Online. En Bonadio, E. y Lucchi, N. (Eds.), Non-conventional copyright: do new and atypical works deserve protection? (pp. 316-339). Edward Elgar Publishing.

Kertysova, K. (2019). Artificial Intelligence and Disinformation. Security and Human Rights, 29(1-4), 55-81.

Kshetri, N. y Voas, J. (2017). The Economics of "Fake News." IT Professional, 19(6), 8-12. https://doi.org/10.1109/mitp.2017.4241459.

Laddie, Prescott y Vitoria. (2018). The modern law of copyright. Lexisnexis.

Lavi, M. (2017). Taking Out of Context. Harvard Journal of Law and Technology, (31), 146-190.

Lewis, T. (2020). Nine COVID-19 Myths That Just Won't Go Away. Scientific American. https://www.scientificamerican.com/article/nine-covid-19-mythsthat-just-wont-go-away.

Lim, D. (2019). AI \& IP: Innovation \& Creativity in an Age of Accelerated Change. Akron Law Review, (52), 814-872.

Mallonee, L. (12 de diciembre de 2016). How Photos Fuel the Spread of Fake News. Wired. https://www.wired.com/2016/12/photos-fuel-spread-fake-news/.

Ohlheiser, A. (18 de noviembre de 2016). This is how Facebook's fake-news writers make money. Washington Post. https://www.washingtonpost.com/news/ the-intersect/wp/2016/11/18/this-is-how-the-internets-fake-news-writersmake-money/. 
Pickard, V. (2020). Confronting the Misinformation Society: Facebook's "Fake News" is a Symptom of Unaccountable Monopoly Power. En McLeod, K. y Zimdars, M. (Eds.), Fake News: Understanding Media and Misinformation inthe Digital Age (pp. 123-132). The MIT Press.

Ping-Hsun, C. (2014). Choice of law-An Unresolved Question in the First Adult Video Copyright Case of the Taiwan Intellectual Property Court, NTUT. Journal of Intellectual Property Law \& Management, 3(1), 56-71.

Pitruzzella, G. y Pollicino, O. (2020). Disinformation and Hate Speech: A European Constitutional Perspective. EGEA Spa - Bocconi University Press.

Rahmatian, A. (2013). Originality in UK Copyright Law: The Old "Skill and Labour" Doctrine Under Pressure. International Review of Intellectual Property and Competition Law, 44(1), 4-34.

Reddy, H., Raj, N., Gala, M. y Basava, A. (2020). Text-mining-based Fake News Detection Using Ensemble Methods. International Journal of Automation and Computing, (17), 210-221.

Rosati, E. (2019). Copyright as an obstacle or an enabler? A European perspective on text and data mining and its role in the development of AI creativity. Asia Pacific Law Review, 27(2), 198-217.

Sanders, A. K. y Jones, R. L. (2018). Clicks at Any Cost: Why Regulation Won't Upend the Economics of Fake News. Business, Entrepreneurship \& Tax Law Review, 2(2), 339-358.

Schulte, S. R. (2020). Fixing Fake News: Self-Regulation and Technological Solutionism. En McLeod, K. y Zimdars, M. (Eds.), Fake News: Understanding Media and Misinformation inthe Digital Age (pp. 133-144). The MIT Press.

Scott, M (27 de marzo de 2018). Cambridge Analytica helped "cheat" Brexit vote and US election, claims whistleblower. POLITICO. https://www.politico.eu/ article/cambridge-analytica-chris-wylie-brexit-trump-britain-data-protection-privacy-facebook.

Sharma, K., Qian, F., Jiang, H., Ruchansky, N., Zhang, M. y Liu, Y. (2019). Combating Fake News. ACM Transactions on Intelligent Systems and Technology, 10(3), 1-42.

Shu, K., Sliva, A., Wang, S., Tang, J. y Liu, H. (2017). Fake News Detection on Social Media. ACM SIGKDD Explorations Newsletter, 19(1), 22-36.

Shu, K., Wang, S., Lee, D. y Liu, H. (Eds.). (2020). Disinformation, misinformation, and fake news in social media: emerging research challenges and opportunities. Springer.

Siebrasse, N. (2001). A Property Rights Theory of the Limits of Copyright. The University Of Toronto Law Journal, (51), 1-61.

Size, R. (2020). Publishing Fake News For Profit Should Be Prosecuted As Wire Fraud. Santa Clara Law Review, (60), 30-99.

Slauter, W. (2019). Who Owns the News?: A History of Copyright (1 ${ }^{\text {a }}$ ed.). Stanford University Press.

Smith, C. Y. N. (2019). Truth, Lies, and Copyright. Nevada Law Journal, (20), 202-222. 
Snow, N. (2015). Content-Based Copyright Denial. Indiana Law Journal, (90), 1474-1523.

Sobel, B. (2017). Artificial Intelligence's Fair Use Crisis. Columbia Journal of Law and the Arts, 41, 45-97.

Solon, O. (12 de febrero de 2016). Facebook won't block fake news posts because it has no incentive, experts say. The Guardian. https://www.theguardian.com/ technology/2016/nov/15/facebook-fake-news-us-election-trump-clinton.

Tandoc (Jr.), E. C., Lim, Z. W. y Ling, R. (2018). Defining "fake news" A typology of scholarly definitions. Digital Journalism, 6(2), 137-153.

Thorne J. y Vlacos A. (2018). Automated Fact Checking: Task formulations, methods and future direction. Proceedings of the 27th International Conference on Computational Linguistics (pp. 3346-3359).

Timmer, J. (2017). Fighting falsity: Fake news, Facebook, and the first amendment. Cardozo Arts \& Entertainment, (35), 669-705.

Tynan, D. (24 de agosto de 2016). How Facebook powers money machines for obscure political "news" sites. The Guardian. https://www.theguardian.com/ technology/2016/aug/24/facebook-clickbait-political-news-sites-us-election-trump.

Vlachos A. y Riedel, S. (2014). Fact checking: Task definition and dataset construction. Proceedings of the ACL 2014 Workshop on Language Technologies and Computational Social Science (pp. 18-22).

Voorhoof, D. (2009). Freedom of Expression under the European Human Rights System. Inter-American and European Human Rights Journal, (2), 3-48.

Zannettou, S., Sirivianos, M., Blackburn, J. y Kourtellis, N. (2019). The Web of False Information. Journal of Data and Information Quality, 11(3), 1-37. 